Archived version from NCDOCKS Institutional Repository http://libres.uncg.edu/ir/asu/

\title{
Appalachl̈ă
}

B O O N E, NORT H C A R O L I A

\section{Language Performance Of Individuals At Risk For Mild Cognitive Impairment}

\author{
By: Kim C. McCullough, Kathryn A. Bayles, and Erin D. Bouldin
}

\begin{abstract}
Evidence exists that changes in language performance may be an early indicator of mild cognitive impairment $(\mathrm{MCl})$, often a harbinger of dementing disease. The purpose of this study was the evaluation of language performance in individuals at risk for $\mathrm{MCl}$ by virtue of age and self-concern and its relation to performance on tests of memory, visuospatial function, and mental status. Eighty-three individuals 55 years or older were administered the Arizona Battery for Communication Disorders of Dementia (Bayles \& Tomoeda, 1993), a standardized battery with normative data from 86 healthy older adults (HOAs) and 86 individuals with Alzheimer's dementia, the most common dementing disease. A performance criterion of 1-1.5 SDs below the mean of HOAs defined $\mathrm{MCl}$, as recommended in the Diagnostic and Statistical Manual of Mental Disorders, Fifth Edition. We hypothesized that (a) the majority of at-risk participants would score 1 SD or more below the mean of HOAs on 1 or more subtests and (b) language performance tests would present a greater challenge than memory, mental status, and visuospatial construction tests. Both hypotheses were confirmed. Sixty-two participants $(74.6 \%)$ met the Diagnostic and Statistical Manual of Mental Disorders, Fifth Edition, criteria on at least 1 subtest. Moreover, language subtests were those most likely to elicit a performance 1 SD or more below the mean of HOAs. Language performance deficits can appear early before impairment in episodic memory, visuospatial construction ability, or mental status in individuals at risk for $\mathrm{MCl}$. Speech-language pathologists are uniquely qualified to identify subtle changes in language, and standardized language tests with normative data should be used when testing for $\mathrm{MCl}$.
\end{abstract}

McCullough, Kim C., Bayles, Kathryn A., Bouldin, Erin D. (2018). Language Performance of Individuals at Risk for Mild Cognitive Impairment. Journal of Speech, Language, and Hearing Research, Vol. 62, No. 3. March 2019, pages 706-722. https://doi.org/10.1044/2018_JSLHR-L-18-0232. Publisher version of record available at: https://pubs.asha.org/doi/full/10.1044/2018_JSLHR-L-18-0232 


\title{
Language Performance of Individuals at Risk for Mild Cognitive Impairment
}

\author{
Kim C. McCullough, ${ }^{\text {a }}$ Kathryn A. Bayles, ${ }^{\text {b }}$ and Erin D. Bouldin ${ }^{\text {C }}$
}

\begin{abstract}
Purpose: Evidence exists that changes in language performance may be an early indicator of mild cognitive impairment $(\mathrm{MCl})$, often a harbinger of dementing disease. The purpose of this study was the evaluation of language performance in individuals at risk for $\mathrm{MCl}$ by virtue of age and self-concern and its relation to performance on tests of memory, visuospatial function, and mental status. Method: Eighty-three individuals 55 years or older were administered the Arizona Battery for Communication Disorders of Dementia (Bayles \& Tomoeda, 1993), a standardized battery with normative data from 86 healthy older adults (HOAs) and 86 individuals with Alzheimer's dementia, the most common dementing disease. A performance criterion of 1-1.5 SDs below the mean of $\mathrm{HOAs}$ defined $\mathrm{MCl}$, as recommended in the Diagnostic and Statistical Manual of Mental Disorders, Fifth Edition. We hypothesized that (a) the majority of at-risk
\end{abstract}

participants would score $1 S D$ or more below the mean of HOAs on 1 or more subtests and (b) language performance tests would present a greater challenge than memory, mental status, and visuospatial construction tests.

Results: Both hypotheses were confirmed. Sixty-two participants (74.6\%) met the Diagnostic and Statistical Manual of Mental Disorders, Fifth Edition, criteria on at least 1 subtest. Moreover, language subtests were those most likely to elicit a performance $1 S D$ or more below the mean of HOAs. Conclusions: Language performance deficits can appear early before impairment in episodic memory, visuospatial construction ability, or mental status in individuals at risk for $\mathrm{MCl}$. Speech-language pathologists are uniquely qualified to identify subtle changes in language, and standardized language tests with normative data should be used when testing for $\mathrm{MCl}$.
A challenge to clinicians and researchers worldwide is early identification of individuals with mild cognitive impairment (MCI), often a harbinger of dementia-producing diseases (Bruscoli \& Lovestone, 2004; Sachdev et al., 2014). Dementia-producing diseases typically develop slowly over many years and even decades in the case of Alzheimer's disease (AD; Albert et al., 2011; Jack et al., 2008; Ohm, Müller, Braak, \& Bohl, 1995; Savica, Rocca, \& Ahlskog, 2010; Sperling et al., 2011; Varghese, Sheelakumari, James, \& Mathuranath, 2013), during which cognitive function gradually deteriorates. Each year, 9.9 million new cases of dementia are reported worldwide or, stated

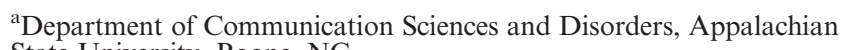
State University, Boone, NC

${ }^{\mathrm{b}}$ Department of Speech, Language, and Hearing Sciences, University of Arizona, Tucson

${ }^{\mathrm{c} D e p a r t m e n t}$ of Health and Exercise Science, Appalachian State University, Boone, NC

Correspondence to Kim C. McCullough: mcculloughkc@appstate.edu
}

another way, every $3 \mathrm{~s}$, someone in the world develops dementia (Alzheimer's Disease International, 2015).

The most common cause of dementia is AD, and approximately 6 million Americans carry that diagnosis. That number is expected to rise to 7.1 million by 2025 (Alzheimer's Association, 2018). Early detection provides those affected with an opportunity to seek pharmacological interventions (Hane et al., 2017; Jack et al., 2018), cognitive therapies (Ngandu et al., 2015), and lifestyle changes (Gorelick et al., 2017; Livingston et al., 2017) that may delay evolution to dementia, thereby significantly reducing health care costs and suffering. According to the Alzheimer's Association, the annual cost to Americans for dementia care now exceeds $\$ 277$ billion dollars, and by 2050 , it will reach $\$ 1.1$ trillion. Detection of MCI in those Americans alive today, who are destined to develop AD, would reduce health care costs by \$7-\$7.9 trillion (Alzheimer's Association, 2018) primarily by preventing the costly comorbidities that often develop in individuals with dementia who are unable to manage their health care. Delaying dementia onset also decreases the incalculable personal and emotional costs to patients and families (Sperling, Karlawish, \& Johnson, 2013).

\footnotetext{
Disclosure: Kathryn A. Bayles is an author of the Arizona Battery for Communication Disorders of Dementia that evolved from support by the National Institute of Aging. All other authors have declared that no competing interests existed at the time of publication.
} 


\section{MCI and DSM-5 Criteria}

MCI can be conceptualized as a probability state that defines a population with a higher risk of developing dementia. It is a heterogeneous clinical entity with many etiologies. Age is the most significant risk factor for dementiaproducing diseases (Keyimu, Zhou, Miao, \& Zou, 2015). Although researchers have identified biomarkers of early disease, testing for them is not routine and has limited impact on the course of an individual's care (Dubois et al., 2016; Hane et al., 2017; Jack et al., 2018; Sperling et al., 2013). Of keen interest, therefore, is identification of the earliest neuropsychological impairments associated with dementing diseases and neuropsychological methods that can detect them (Albert et al., 2011; Chen \& Wang, 2013; Chong \& Sahadevan, 2005; Dubois et al., 2016; Loftus, 2017; Mueller, Koscik, Hermann, Johnson, \& Turkstra, 2018).

With the publication of the fifth edition of the Diagnostic and Statistical Manual of Mental Disorders (DSM-5; American Psychiatric Association, 2013), clinicians and researchers were given guidance about neuropsychological testing for MCI and criteria for making a diagnosis. The DSM-5 authors use the following criteria to define MCI:

1. Evidence of modest cognitive decline from a previous level of performance in one or more cognitive domains (complex attention, language, learning and memory, executive function, visuoconstruction [perceptual motor], and social cognition) based on

a. concern of the individual, a knowledgeable informant, or the clinician that there has been mild decline in cognitive function; and

b. a modest impairment in cognitive performance, preferably documented by standardized neuropsychological testing or, in its absence, other quantified clinical assessments.

2. The cognitive deficits do not interfere with capacity for independence in everyday activities of daily living (ADLs). Basic ADLs include the ability to feed, dress, bathe self, and manage toileting. Assistance with more complex tasks might be needed.

The DSM-5 authors recommended using standardized batteries that assess several cognitive domains for which there are age-appropriate norms for healthy adults. Six cognitive domains were specified for consideration: language, perceptual motor ability (visuospatial construction), executive function, learning and memory, complex attention, and social cognition. The following performance cutoffs were specified for diagnosing MCI and differentiating it from dementia: A performance of $1-2 S D$ s below ageappropriate norms (the third and 16th percentiles) was designated as indicative of MCI; a performance of $2 S D$ s or more below age-appropriate norms (the third percentile or below) was designated as indicative of dementia. Of the six $D S M-5$ specified cognitive domains, deficits in memory, executive function, and language are those most frequently reported (Chong \& Sahadevan, 2005; Cottingham \&
Hawkins, 2010; Kirova, Bays, \& Lagalwar, 2015; Petersen, 2004; Petersen \& Negash, 2008; Petersen et al., 2014; Tsantali, Economidis, \& Tsolaki, 2013). Whereas changes in memory and executive function have been well characterized, much less is known about the nature of language impairment (Díaz-Mardomingo, García-Herranz, RodríguezFernández, Venero, \& Peraita, 2017; Kirova et al., 2015).

\section{MCI and Language Impairment}

An early report of a possible relation between language ability and vulnerability to dementia came from the now famous Nun Study (Riley, Snowdon, Desrosiers, \& Markesbery, 2005; Snowdon et al., 1996). Snowdon and colleagues hypothesized that linguistic ability in early life may be related to development of dementia in older age because linguistic ability is a marker of cognitive strength. This hypothesis was tested with support of the School Sisters of Notre Dame in Mankato, Minnesota. The sisters were 75-95 years of age, and all wrote autobiographies in their early 20 s before taking their vows. Their autobiographies were handwritten without support from others. The sisters gave permission for them to be analyzed and also agreed to take a battery of neuropsychological tests and postmortem analysis of their brains. Because the sisters lived together for decades and had the same housing, diet, and access to medical care and, in most cases, were teachers, many potentially confounding variables were controlled.

Snowdon and colleagues observed that approximately $80 \%$ of the autobiographies with less idea density and grammatical complexity were written by nuns who later developed dementia as confirmed by neuropsychological testing and postmortem analysis. Only 10\% of the sisters whose autobiographies had greater idea density and grammatical complexity developed dementia. The criteria used to define dementia were as follows: sufficient cognitive impairment to interfere with social functioning and ADLs and a neuropsychological test score below the 10th percentile of the scores of healthy older adults (HOAs).

The findings of Snowdon and colleagues stimulated interest in the relation of language performance to onset of dementia-producing diseases, and the literature contains many reports of language performance deficits in individuals with confirmed MCI (Asgari, Kaye, \& Dodge, 2017; Bertola et al., 2014; Cardoso, Silva, Maroco, Mendonça, \& Guerreiro, 2014; Choi, Kim, Lee, \& Kim, 2013; Costa et al., 2014; Kim, Sung, \& Jeong, 2012; Mueller et al., 2018, 2015; Nutter-Upham et al., 2008; Payne \& StineMorrow, 2016; Smolik et al., 2016; Tsantali et al., 2013; Vaughan, Coen, Kenny, \& Lawlor, 2016; Weakley, Schmitter-Edgecombe, \& Anderson, 2013) and those with clinically diagnosed dementia (Bayles, McCullough, \& Tomoeda, 2018; Bayles, Tomoeda, \& Trosset, 1992; Tomoeda \& Bayles, 1993; Tomoeda, Bayles, Trosset, Azuma, \& McGeagh, 1996). The most commonly reported language performance deficit in individuals with MCI is impaired verbal fluency as measured by having individuals name as many items as possible in a category 
(Albert et al., 2011; Clark et al., 2013; Irish et al., 2011; Malek-Ahmadi, Raj, \& Small, 2011; Tsantali et al., 2013; Weakley et al., 2013). Demetriou and Holtzer (2017) reported that individuals with MCI generated fewer words compared to controls during the first $20 \mathrm{~s}$ and in succeeding intervals in both phonemic and category verbal fluency tests. They reported a Group $\times$ Time interaction and concluded that MCI is characterized by deficits in "early automatic retrieval processes." More recently, middle-aged individuals categorized as having "early" MCI were reported to have deficits in verbal fluency and connected language (Johnson et al., 2017; Mueller et al., 2015, 2016).

Impairment in confrontation naming in individuals with MCI has also been reported (Ahmed, Arnold, Thompson, Graham, \& Hodges, 2008; Dwolatzky et al., 2003; Grundman et al., 2004; Petersen et al., 1999). Ahmed et al. (2008) administered three naming tasks to participants with MCI: black and white drawings of highly familiar objects, pictures of famous faces, and pictures of famous buildings. Performance on all three tasks was poorer for participants with MCI when compared to the healthy control group.

Tsantali et al. (2013) conducted a study to evaluate language in participants with amnestic MCI, those with mild $\mathrm{AD}$, and HOAs. Language performance was evaluated using the Boston Diagnostic Aphasia Examination. Participant performance on the Boston Diagnostic Aphasia Examination subtests of animal naming, nonverbal agility, comprehension of oral spelling, reading of phrases and paragraphs, automatized sentences, and naming response discriminated participants with MCI from healthy controls $84.9 \%$ of the time. These findings indicate a need for a comprehensive language assessment of individuals at risk for MCI.

Language deficits have also been found to be a strong predictor of conversion from MCI to dementia. Oulhaj, Wilcock, Smith, and de Jager (2009) followed 241 HOAs for up to 20 years to identify early markers of MCI. Participants were periodically administered the Cambridge Cognitive Examination (CAMCOG; Roth, Huppert, Tym, \& Mountjoy, 1998), a comprehensive neuropsychological battery comprising subtests of orientation, comprehension, expression, recent memory, remote memory, learning, abstract thinking, perception, praxis, attention, and calculation. They reported that performance on language expression subtests was a stronger predictor of duration to conversion than performance on or memory subtests. The CAMCOG expression subtest includes verbal fluency, spoken language descriptions, and definitions. For each point lower on the CAMCOG expression score, the time to conversion was $17 \%$ shorter; for each point lower on the learning score, the time to conversion was $15 \%$ shorter; and for every 5 years of age, time to conversion was $14 \%$ shorter. Oulhaj et al. also reported that performance on language expression tests, rather than memory tests, is a stronger predictor of duration to conversion to AD. These authors used the following tasks to characterize language expression: object naming, category fluency, word definitions, sentence repetition, and a spontaneous description of the "cookie theft" picture.
Whereas language performance deficits have been widely reported in individuals with confirmed MCI, little is known about the language expression and comprehension abilities of individuals at risk for MCI by virtue of age and self-concern about their cognitive function (DíazMardomingo et al., 2017). Thus, we undertook to evaluate language performance in individuals at risk for MCI. The Arizona Battery for Communication Disorders of Dementia (ABCD; Bayles \& Tomoeda, 1993), a standardized battery with tests of language comprehension and production, verbal episodic memory, visuospatial construction, and mental status, was used. The ABCD evolved from National Institutes of Health, National Institute on Aging (NIH-NIA)-supported longitudinal studies of individuals with mild and moderate dementia and was designed to quantify cognitive-linguistic impairment. Moreover, the $\mathrm{ABCD}$ has the features recommended by the authors of the DSM-5: subtests for evaluating several cognitive domains, more than one subtest with which to evaluate each cognitive domain, and normative data for HOAs as well as young adults and individuals with mild and moderate AD.

Two hypotheses were formed based on three facts: first, that dementia-associated diseases start decades before behavioral deficits are obvious; second, the Nun Study finding that early-life linguistic ability was associated with vulnerability to late-life dementia; and, third, the many reports of language performance deficits in individuals with MCI. We hypothesized that the majority of individuals at risk for MCI, by virtue of age and a concern about their cognitive function, would score $1 S D$ or more below the mean of HOAs on one or more ABCD subtests and that language performance tests would present a greater challenge to at-risk individuals than tests of episodic memory, mental status, and visuospatial construction. The possibility that language performance impairments are early indicators of MCI is of considerable significance to speech-language pathologists (SLPs), who are uniquely qualified to detect subtle language impairment by virtue of their training.

\section{Method \\ Participants}

This study was approved by the institutional research review boards of the University of Central Arkansas and Appalachian State University. Study participants were recruited from senior centers and community programs and by word of mouth. Recruitment materials and oral presentations about the study included information that encouraged those with concern about memory or thinking to consider participation. We designated 55 years as the minimum age because HOAs typically have degenerative changes in the brain by this time, as do individuals who are in the prodromal stage of a dementing disease (Nyberg \& Bäckman, 2011; Peters, 2006). All potential participants aged 55 years and older were asked by the interviewer: "Are you concerned about changes in your memory or thinking?" and all indicated they had concern. All were 
informed that they would be given a standardized neuropsychological battery comprising tests of language, memory, visuospatial abilities, and mental status and their performance scores would be compared to those of adults in the standardization study. Participants signed consent to cognitivelinguistic testing and the use of their performance data. All met the following inclusionary criteria: were at least 55 years of age and native speakers of English, had concern about change in cognitive ability, reported no history of neurologic or psychiatric disorders, and lived in their own homes. None had home care or attended day care programs. All reported being able to perform basic ADLs. Basic ADLs were explained to the participants as the ability to feed, dress, bathe self, and manage toileting. A speech discrimination hearing test and tests of visual perception and literacy were administered to candidates to rule out conditions that could confound test performance.

Eighty-three individuals participated in the study, and their demographic characteristics are shown in Table 1. Their average age was 73 years, most were women (73\%), and their average years of education was 15.02. Study participants were well matched with participants in the ABCD standardization sample whose average age was 70 years, most were women $(72 \%)$, and their average years of education was 13.72 .

\section{Assessment}

\section{ABCD}

As previously noted, the ABCD was selected for use in this study because it has the features recommended by authors of the $D S M-5$ and has been in wide use by SLPs for more than 20 years. Results of NIH-NIA supported longitudinal and cross-sectional studies of the cognitivelinguistic and memory abilities of individuals with dementia and HOAs were the basis for the development of the ABCD (Bayles et al., 1992; Bayles, Tomoeda, \& Trosset, 1993; Bayles, Tomoeda, Wood, Cruz, \& Mcgeagh, 1996; Tomoeda \& Bayles, 1993). The battery comprises 14 subtests (one subtest has four scores for a total of 17 scores) that evaluate the domains of language, memory, visuospatial construction, and mental status. Its purpose is not to characterize degree of intelligence but to identify impairment in language performance, memory, visuospatial construction ability, and mental status. Thus, the vocabulary and visual stimuli used in the battery are common and familiar to neurologically healthy, literate English-speaking adults. This fact is a key feature of the battery and accounts for neurologically healthy individuals scoring at or near ceiling on all the subtests.

The ABCD standardization study had 272 participants: 86 individuals with AD, 62 nondemented individuals with Parkinson's disease, eight individuals with Parkinson's dementia, 86 age-matched HOAs, and 30 healthy young adults. Participants met the following criteria: spoke English as a first language, were literate, had no history of alcohol or drug abuse, had no history of previous neurologic or psychiatric disorders, lived at home, and had typical estimated premorbid intelligence. All were in good to excellent health. None had significant cardiovascular, renal, hepatic, gastrointestinal, pulmonary, or hematologic

Table 1. Demographic characteristics of study participants overall and by the number of subtests on which they scored $1 S D$ below the mean of healthy older adults (HOAs).

\begin{tabular}{|c|c|c|c|c|c|c|}
\hline \multirow[b]{2}{*}{ Variable } & \multirow[b]{2}{*}{ Category } & \multirow{2}{*}{$\frac{\text { All }(N=83)}{n(\%)}$} & \multicolumn{4}{|c|}{ Number of scores below HOAs ${ }^{a}$} \\
\hline & & & $\frac{0(n=21)}{n(\%)}$ & $\frac{1(n=15)}{n(\%)}$ & $\frac{2-3(n=20)}{n(\%)}$ & $\frac{\geq 4(n=27)}{n(\%)}$ \\
\hline \multirow[t]{3}{*}{ Age (years) } & $M(S D)$ & $73.3(11.1)$ & $65.8(8.3)$ & $69.6(11.8)$ & $77.1^{\mathrm{b}}(10.5)$ & $78.4^{\mathrm{b}}(9.3)$ \\
\hline & $55-64$ & $24(28.9)$ & $13(61.9)$ & $6(40.0)$ & $3(15.0)^{b}$ & $2(7.4)^{b}$ \\
\hline & $65-74$ & $16(19.3)$ & $2(9.5)$ & $3(20.0)$ & $3(15.0)$ & $8(29.6)$ \\
\hline \multirow[t]{2}{*}{ Sex } & Male & $23(27.7)$ & $5(23.8)$ & $4(26.7)$ & $5(75.0)$ & 9 (33.3) \\
\hline & Female & $60(72.3)$ & $16(76.2)$ & $11(73.3)$ & $15(25.0)$ & $18(66.7)$ \\
\hline \multirow[t]{3}{*}{ Race/ethnicity } & White, non-Hispanic & $77(92.8)$ & $19(90.5)$ & $14(93.3)$ & $20(100)$ & $24(88.9)$ \\
\hline & Black, non-Hispanic & $3(3.6)$ & $2(9.5)$ & $1(6.7)$ & $0(0)$ & $1(3.7)$ \\
\hline & Any race, Hispanic & $3(3.6)$ & $0(0)$ & $0(0)$ & $0(0)$ & $2(7.4)$ \\
\hline \multirow{2}{*}{ Years of education } & $<12$ & $6(7.1)$ & $1(4.8)$ & $0(0)$ & $1(5.0)$ & $4(14.8)$ \\
\hline & 12 & $12(14.5)$ & $1(4.8)$ & $1(6.7)$ & $4(20.0)$ & $6(22.2)$ \\
\hline
\end{tabular}

Note. For age categories, the asterisk represents a different trend across age groups; we did not test age groups individually because they are ordered.

ascoring below HOAs was defined as a score > $1 S D$ below the mean for HOAs in the Arizona Battery for Communication Disorders of Dementia standardization study. 'S Statistically significant difference $(p<.05)$ between groups who had no item scores below HOAs and indicated group based on a $t$ test with unequal variance for mean age and a chi-square test for all other (categorical) variables. 
conditions or neoplastic disease in the previous 5 years. None scored less than 4 on the modified Hachinski Ischemic Scale (Hachinski et al., 1975), a screening test for vascular disease, and all passed a screening test for depression. Additionally, all had visual acuity sufficient to read 18-point font print (size of print in the test) and passed a speech discrimination hearing test with $80 \%$ or better accuracy.

$\mathrm{ABCD}$ subtests scores can be considered individually or grouped to compute construct/domain scores (for mental status, episodic memory, linguistic expression, linguistic comprehension, or visuospatial construction) or an overall score. Standardization subtest scores for HOAs and individuals with mild $\mathrm{AD}$ are shown in Table 2.

\section{Reliability and Validity of $A B C D$}

The ABCD has excellent test-retest reliability (see Table 3). Twenty of the patients with AD were tested twice a week apart. None had intercurrent illness. The "learning effect," in Table 3, is the mean of the retest-minus-test scores and is tested by computing a one-sample $t$ statistic. The learning effect rarely differed significantly from zero. Stability is inferred from testing the null hypothesis of no test-retest correlation. Two correlation statistics were computed: (a) the coefficient of determination, $r^{2}$, which equals the square of Pearson's $r$, and (b) the probability of concordance. Both measures are high for most subtests. When this is not the case, it does not necessarily mean that reliability is low. Rather, it may mean that there is insufficient variability in performances to result in a meaningful ordering of the subjects. This usually occurs because a task is very easy or hard. In the case of Story Retelling: Delayed, there was no variability. Each of the 20 subjects with AD scored 0 on the test and retest.

Cronbach's alpha was calculated to answer the reliability question related to internal consistency (see Table 4). Cronbach's alpha ranges from 0 to 1 , where a value of 0 indicates no internal consistency and a value of 1 indicates perfect internal constancy. Cronbach's alpha is affected by the number of test items. Because Object Description, Generative Naming, and Generative Drawing do not comprise fixed items, the notion of internal consistency is not germane to them.

Criterion validity was determined through correlation of the ABCD subtest scores with three measures of dementia severity: the Global Deterioration Scale (Reisberg, Ferris, de Leon, \& Crook, 1982, 1998), the Mini-Mental State Examination (Folstein, Folstein, \& McHugh, 1975), and the Block Design subtest of the Wechsler Adult Intelligence Scale-Revised (Wechsler, 1981). Correlations between these three measures and $\mathrm{ABCD}$ subtests were high, ranging from .62 to .85 (Bayles \& Tomoeda, 1993; see Table 5).

Table 2. Mean subtest scores and standard deviations of the Arizona Battery for Communication Disorders of Dementia (ABCD) standardization study participants—healthy older adults (HOAs) and people with mild Alzheimer's disease (AD)—and among this study's participants.

\begin{tabular}{|c|c|c|c|c|c|c|}
\hline \multirow[b]{3}{*}{ ABCD domain and subtest } & \multicolumn{4}{|c|}{ ABCD standardization study } & \multirow{2}{*}{\multicolumn{2}{|c|}{$\begin{array}{l}\text { All participants } \\
\quad(N=83)\end{array}$}} \\
\hline & \multicolumn{2}{|c|}{ HOA } & \multicolumn{2}{|c|}{ Mild AD } & & \\
\hline & $M$ & $\overline{S D}$ & $M$ & $\overline{S D}$ & $M$ & $S D$ \\
\hline \multicolumn{7}{|l|}{ Linguistic expression } \\
\hline Object Description & 9.1 & 2.4 & 6.6 & 3.1 & $8.6^{\mathrm{a}}$ & 3.1 \\
\hline Generative Naming & 11.4 & 3.4 & 7.1 & 3.5 & $9.6^{a, b}$ & 2.3 \\
\hline Confrontation Naming & 18.1 & 2.3 & 15.5 & 2.8 & $18.2^{\mathrm{a}}$ & 1.9 \\
\hline Concept Definition & 56.6 & 5.0 & 41.2 & 11.3 & $52.6^{a, b}$ & 9.5 \\
\hline \multicolumn{7}{|l|}{ Linguistic comprehension } \\
\hline Following Commands & 8.8 & 0.4 & 8.3 & 1.0 & 8.6 & 0.7 \\
\hline Comparative Questions & 5.9 & 0.5 & 5.7 & 0.6 & 5.9 & 0.3 \\
\hline Repetition & 67.9 & 7.0 & 59.2 & 11.5 & $62.0^{\mathrm{b}}$ & 10.3 \\
\hline Reading Comprehension: Word & 7.9 & 0.7 & 7.7 & 0.6 & 7.9 & 0.3 \\
\hline Reading Comprehension: Sentences & 6.4 & 0.9 & 6.0 & 1.2 & 6.5 & 0.8 \\
\hline \multicolumn{7}{|l|}{ Verbal episodic memory and learning } \\
\hline Story Retelling: Immediate & 14.0 & 2.8 & 7.3 & 4.1 & $13.4^{\mathrm{a}}$ & 2.5 \\
\hline Story Retelling: Delayed & 12.4 & 4.5 & 1.0 & 2.6 & $12.5^{\mathrm{a}}$ & 3.7 \\
\hline Word Learning: Free Recall & 7.6 & 2.5 & 2.3 & 1.9 & $8.4^{\mathrm{a}}$ & 2.5 \\
\hline Word Learning: Total Recall & 15.1 & 1.2 & 7.7 & 3.9 & $15.3^{\mathrm{a}}$ & 1.0 \\
\hline Word Learning: Recognition & 46.6 & 2.5 & 36.3 & 7.7 & $47.0^{\mathrm{a}}$ & 1.2 \\
\hline \multicolumn{7}{|l|}{ Visuospatial construction } \\
\hline Generative Drawing & 12.4 & 1.6 & 10.7 & 3.0 & $13.2^{\mathrm{a}}$ & 1.4 \\
\hline Figure Copying & 11.4 & 1.0 & 11.1 & 1.9 & 11.7 & 0.6 \\
\hline \multicolumn{7}{|l|}{ Mental status } \\
\hline Mental Status & 12.8 & 0.6 & 9.9 & 2.6 & $12.8^{\mathrm{a}}$ & 0.5 \\
\hline
\end{tabular}


Table 3. Test-retest reliability of the Arizona Battery for Communication Disorders of Dementia subtests.

\begin{tabular}{|c|c|c|c|}
\hline \multirow[b]{2}{*}{ Subtest } & \multirow[b]{2}{*}{ Learning effect } & \multicolumn{2}{|c|}{ Correlation } \\
\hline & & $r^{2}$ & $p$ (concordance) \\
\hline Mental Status & 0.15 & $.74^{\star \star \star}$ & $.85^{\star \star \star}$ \\
\hline Story Retelling: Immediate & $1.30^{*}$ & $.50^{\star \star \star}$ & $.79^{\star \star \star}$ \\
\hline Following Commands & 0.20 & $.39^{\star \star}$ & $.73^{\star}$ \\
\hline Comparative Questions & 0.05 & $.59^{\star \star \star}$ & $.85^{\star \star \star}$ \\
\hline Word Learning: Free Recall & 0.10 & $.34^{*}$ & $.74^{\star}$ \\
\hline Word Learning: Total Recall & $1.65^{\star}$ & $.46^{\star \star}$ & $.77^{\star \star}$ \\
\hline Word Learning: Recognition & 0.35 & $.34^{*}$ & $.65^{\star}$ \\
\hline Repetition & $4.22^{*}$ & $.56^{\star \star \star}$ & $.79^{\star \star \star}$ \\
\hline Object Description & 0.25 & $.53^{\star \star \star}$ & $.77^{\star \star}$ \\
\hline Reading Comprehension: Word & 0.35 & .01 & .55 \\
\hline Reading Comprehension: Sentence & -0.05 & $.50^{\star \star \star}$ & $.81^{\star \star \star}$ \\
\hline Generative Naming & -0.70 & $.47^{\star \star}$ & $.80^{\star \star \star}$ \\
\hline Confrontation Naming & $1.90^{\star \star \star}$ & $.74^{\star \star \star}$ & $.87^{\star \star \star}$ \\
\hline Concept Definition & 0.50 & $.44^{\star *}$ & $.70^{\star}$ \\
\hline Generative Drawing & 0.15 & $.68^{\star \star \star}$ & $.82^{\star \star \star}$ \\
\hline Figure Copying & -0.30 & $.86^{\star \star \star}$ & $.77^{\star \star}$ \\
\hline Picture Description & 5.84 & $.40^{\star \star}$ & $.69^{\star}$ \\
\hline Story Retelling: Delayed & $\mathrm{n} / \mathrm{a}$ & $\mathrm{n} / \mathrm{a}$ & $\mathrm{n} / \mathrm{a}$ \\
\hline
\end{tabular}

${ }^{\star}$ Two-sided $p \leq .05$. ${ }^{\star *}$ Two-sided $p \leq .005$. ${ }^{\star * \star}$ Two-sided $p \leq .0005$.

Interrater reliability of subtest scoring (interrater agreement) ranged from $93 \%$ to $100 \%$.

In a poststandardization study, Bayles et al. (1996) compared the ABCD overall score to five measures known to be sensitive to dementia to determine which was the best for discriminating individuals with early medically diagnosed AD from HOAs: the Modified Wisconsin Card Sorting Test (Hart, Kwentus, Wade, \& Taylor, 1988), a test of verbal fluency (Bayles, Trosset, Tomoeda, Montgomery, \& Wilson, 1993), a verbal picture description test (Tomoeda \& Bayles, 1993), and the Mini-Mental State Examination. The ABCD was the best measure for discriminating mild $\mathrm{AD}$ and for distinguishing mild from moderate AD.

Table 4. Internal consistency of the Arizona Battery for Communication Disorders of Dementia subtests.

\begin{tabular}{lc}
\hline Subtest & Cronbach's a \\
\hline Mental Status & .8448 \\
Story Retelling & .8557 \\
Following Commands & .6962 \\
Comparative Questions & .5017 \\
Word Learning: Free Recall & .6320 \\
Word Learning: Total Recall & .8155 \\
Word Learning: Recognition & .8447 \\
Repetition & .8002 \\
Object Description & $\mathrm{n} / \mathrm{a}$ \\
Reading Comprehension: Word & .6735 \\
Reading Comprehension: Sentence & .6898 \\
Generative Naming & $\mathrm{n} / \mathrm{a}$ \\
Confrontation Naming & .8772 \\
Concept Definition & .8389 \\
Generative Drawing & $\mathrm{n} / \mathrm{a}$ \\
Figure Copying & .9179 \\
Picture Description & $\mathrm{n} / \mathrm{a}$ \\
Story Retelling: Delayed & .9853 \\
\hline
\end{tabular}

\section{Testing Procedure for At-Risk Participants}

Study participants were administered the full ABCD in one session in a quiet, well-lit environment. In no case was another person present during testing. Testing usually

Table 5. Correlations of the Arizona Battery for Communication Disorders of Dementia (ABCD) subtests with three accepted measures of dementia severity.

\begin{tabular}{|c|c|c|c|}
\hline \multirow[b]{2}{*}{ Subtest } & \multicolumn{3}{|c|}{$p$ (of concordance) } \\
\hline & GDS $^{a}$ & MMSE & Block \\
\hline Mental Status & $.82^{\star \star \star}$ & $.85^{\star \star \star}$ & $.71^{\star \star \star}$ \\
\hline Story Retelling: Immediate & $.75^{\star \star \star}$ & $.74^{\star \star \star}$ & $.71^{\star \star \star}$ \\
\hline Following Commands & $.73^{\star \star \star}$ & $.79^{\star \star \star}$ & $.75^{\star \star \star}$ \\
\hline Comparative Questions & $.66^{\star}$ & $.68^{\star \star}$ & $.67^{\star \star}$ \\
\hline Word Learning: Free Recall & $.67^{\star \star}$ & $.70^{\star \star \star}$ & $.64^{*}$ \\
\hline Word Learning: Total Recall & $.71^{\star \star \star}$ & $.71^{\star \star \star}$ & $.65^{\star \star}$ \\
\hline Word Learning: Recognition & $.66^{\star \star}$ & $.66^{\star \star}$ & $.59^{\star}$ \\
\hline Repetition & $.66^{\star \star}$ & $.70^{\star \star \star}$ & $.66^{\star \star}$ \\
\hline Object Description & $.73^{\star \star \star}$ & $.73^{\star \star \star}$ & $.67^{\star \star}$ \\
\hline Reading Comprehension: Word & $.72^{\star \star \star}$ & $.72^{\star \star \star}$ & $.65^{\star \star}$ \\
\hline Reading Comprehension: Sentence & $.71^{\star \star \star}$ & $.74^{\star \star \star}$ & $.70^{\star \star \star}$ \\
\hline Generative Naming & $.73^{\star \star \star}$ & $.78^{\star \star \star}$ & $.74^{\star \star \star}$ \\
\hline Confrontation Naming & $.77^{\star \star \star}$ & $.75^{\star \star \star}$ & $.68^{\star \star \star \star}$ \\
\hline Concept Definition & $.72^{\star \star \star}$ & $.73^{\star \star \star}$ & $.63^{*}$ \\
\hline Generative Drawing & $.73^{\star \star \star}$ & $.77^{\star \star \star}$ & $.76^{\star \star \star}$ \\
\hline Figure Copying & $.68^{\star \star}$ & $.72^{\star \star \star}$ & $.74^{\star \star \star}$ \\
\hline Picture Description & $.66^{\star \star}$ & $.70^{\star \star \star}$ & $.69^{\star \star \star}$ \\
\hline Story Retelling: Delayed & $.63^{*}$ & $.62^{\star}$ & $.62^{*}$ \\
\hline
\end{tabular}

Note. GDS = Global Deterioration Scale; MMSE = Mini-Mental State Examination; Block = Wechsler Adult Intelligence Scale-Revised Block Design subtest.

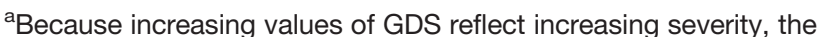
$A B C D$ tasks were correlated with the negative of the GDS values.

${ }^{\star}$ Two-sided $p \leq .05$. ${ }^{* \star}$ Two-sided $p \leq .005$. ${ }^{* \star * T w o-s i d e d ~} p \leq .0005$. 
took an hour but never exceeded $90 \mathrm{~min}$. No individuals expressed fatigue. Test performance scores were doublechecked for accuracy and computerized.

\section{Data Analyses}

A multistep analysis of data was conducted using Stata 13.1. In Step 1, we identified the number of at-risk individuals who scored at least $1 S D$ below the mean of HOAs on one or more ABCD subtests. As previously noted, the criterion of $1 S D$ was recommended in the DSM-5 and by the NIA-AA taskforce (Albert et al., 2011; American Psychiatric Association, 2013) as an appropriate cutoff for differentiating individuals with MCI from HOAs.

In Step 2, a comparison was made of the mean subtest scores of the at-risk individuals to the subtest scores of the HOAs and subjects with mild AD in the ABCD standardization study. We used one-sided two-sample $t$ tests with unequal variance to make these comparisons. Because there are 17 subtest scores in the ABCD (the Word Learning subtest has four scores), the Bonferroni correction for multiple comparisons (Dunn, 1961) was used and a $p$ value of $<.003$ was selected to indicate statistical significance.

In Step 3, study participants were categorized according to the number of subtests on which they scored below the mean of HOAs ( 0 subtests, 1 subtest, 2-3 subtests, and $\geq 4$ subtests). A calculation was then made of the percentage of individuals, in each of these groups $(1,2-3$, and $\geq 4)$, who scored $1 S D$ or more below the mean of HOAs on each subtest and within each domain (language expression and comprehension, memory, visuospatial construction, mental status).

In Step 4, the mean subtest performances of at-risk participants with performance scores above $1 S D$ below the mean on all ABCD subtests $(N=21)$ were averaged and compared to the average scores of at-risk participants who scored below HOAs on one or more subtests. We used one-sided $t$ tests with unequal variance as well as linear regression models to make these comparisons. Adjustments were made for age and education because of the relation of these factors to cognitive ability.

In Step 5, the final analysis, we changed the cutoff for significance from $1 S D$ to $1.5 S D$ s below the mean of HOAs. Thereafter, we calculated the percentage of at-risk participants who performed below HOAs using the 1.5-SD criterion.

\section{Results}

\section{Hypothesis 1: The Majority of At-Risk Individuals Would Score 1 SD or More Below the Mean of HOAs on One or More ABCD Subtests}

This hypothesis was confirmed. Sixty-two of the 83 study participants $(74.6 \%)$ scored at least $1 S D$ below the mean of HOAs in the standardization study on at least one ABCD subtest. Fifteen study participants (18\%) scored below HOAs on 1 subtest, 20 (24\%) scored below HOAs on 2-3 subtests, and $27(33 \%)$ scored below HOAs on $\geq 4$ subtests (see Table 6). When we changed the criterion for MCI to $1.5 \mathrm{SDs}$ below the mean of HOAs, the majority of study participants $(N=48,57.8 \%)$ still had at least one subtest score that was lower than HOAs in the ABCD standardization study (see Table 7).

\section{Hypothesis 2: Language Performance Subtests Will Present a Greater Challenge to At-Risk Individuals Than Tests of Episodic Memory, Mental Status, and Visuospatial Construction}

This hypothesis was confirmed. Of the study participants who scored at least $1 S D$ below the mean of HOAs on at least one ABCD subtest, $79 \%$ did so on a linguistic comprehension subtest, $62.9 \%$ on a linguistic expression subtest, $38.7 \%$ on an episodic memory subtest, $27.4 \%$ on the mental status subtest, and $14.5 \%$ on a visuospatial construction subtest (see Table 6). Moreover, when study participants were grouped by the number of subtests on which they scored below HOAs $(1,2-3$, or $\geq 4)$, the language comprehension and expression subtests were still those most challenging.

Additionally, when the criterion of $1.5 S D$ s below the mean of HOAs was used, Hypothesis 2 was still confirmed. Specifically, the linguistic comprehension and linguistic expression subtests were those on which the scores of study participants were most likely to be at least $1.5 \mathrm{SDs}$ lower than those of HOAs. In fact, the percentage of the participants who scored 1.5 SDs below HOAs on the various ABCD subtests was very similar to the percentages obtained with the criterion of $1 S D$ below the mean (see Table 8).

When the subtest performance scores of at-risk study participants were compared to those of HOAs, the scores of at-risk participants were statistically significantly $(p<.003)$ lower on three language performance subtests (see Table 2): Generative Naming, Concept Definition, and Repetition. When their scores were compared to those of the participants with mild probable AD in the ABCD standardization study, the scores of the at-risk participants were statistically significantly $(p<.003)$ higher on 11 of the subtests (see Table 2).

The subtest means of the at-risk participants who scored above $1 S D$ below the mean $(N=21)$ were compared to those scoring at least $1 S D$ below the mean of HOAs on one or more ABCD subtests $(N=62$; see Table 9). Performance means for all groups $(1,2-3$, and $=4)$ were significantly lower than the mean of participants who scored greater than $1 S D$ below the mean (group 0) on only one subtest: Object Description (nail stimulus). For no other ABCD subtest were the means of Group 1 significantly lower than those of the participants who scored above $1 S D$ below the mean. Three subtests differentiated the participants who scored greater than $1 S D$ below the mean from those 
Table 6. Percentage of study participant groups who scored $1 S D$ below healthy older adults (HOAs) on each subtest and by domain.

\begin{tabular}{|c|c|c|c|c|}
\hline \multirow[b]{3}{*}{$A B C D$ domain and subtest } & \multicolumn{4}{|c|}{ Number of scores below HOAs ${ }^{a}$} \\
\hline & $\geq 1(n=62)$ & $1(n=15)$ & $2-3(n=20)$ & $\geq 4(n=27)$ \\
\hline & $\%$ & $\%$ & $\%$ & $\%$ \\
\hline \multicolumn{5}{|l|}{ Linguistic expression } \\
\hline Object Description & 30.6 & 0 & 40.0 & 40.7 \\
\hline Generative Naming & 24.2 & 6.7 & 20.0 & 37.0 \\
\hline Confrontation Naming & 12.9 & 0 & 5.0 & 25.9 \\
\hline Concept Definition & 35.5 & 13.3 & 15.0 & 63.0 \\
\hline Any subtest in domain & 62.9 & 20.0 & 70.0 & 81.5 \\
\hline \multicolumn{5}{|l|}{ Linguistic comprehension } \\
\hline Following Commands & 38.7 & 13.3 & 35.0 & 55.6 \\
\hline Comparative Questions & 12.9 & 0 & 15.0 & 18.5 \\
\hline Repetition & 54.8 & 20.0 & 55.0 & 74.1 \\
\hline Reading Comprehension: Word & 14.5 & 13.3 & 5.0 & 22.2 \\
\hline Reading Comprehension: Sentences & 12.9 & 6.7 & 5.0 & 22.2 \\
\hline Any subtest in domain & 79.0 & 53.3 & 85.0 & 88.9 \\
\hline \multicolumn{5}{|l|}{ Verbal episodic memory and learning } \\
\hline Story Retelling: Immediate & 19.4 & 6.7 & 10.0 & 33.3 \\
\hline Story Retelling: Delayed & 11.3 & 0 & 5.0 & 22.2 \\
\hline Word Learning: Free Recall & 21.0 & 13.3 & 10.0 & 33.3 \\
\hline Word Learning: Total Recall & 6.5 & 0 & 0 & 14.8 \\
\hline Word Learning: Recognition & 4.8 & 0 & 0 & 11.1 \\
\hline Any subtest in domain & 38.7 & 20.0 & 20.0 & 63.0 \\
\hline \multicolumn{5}{|l|}{ Visuospatial construction } \\
\hline Generative Drawing & 4.8 & 0 & 0 & 11.1 \\
\hline Figure Copying & 12.9 & 0 & 0 & 29.6 \\
\hline Any subtest in domain & 14.5 & 0 & 0 & 33.3 \\
\hline \multicolumn{5}{|l|}{ Mental status } \\
\hline Mental Status & 27.4 & 6.7 & 20.0 & 44.4 \\
\hline
\end{tabular}

Note. $\mathrm{ABCD}=$ Arizona Battery for Communication Disorders of Dementia.

aScoring below HOAs was defined as a score of $>1 S D$ below the mean for HOAs in the ABCD standardization study.

who scored at least $1 S D$ below the mean of HOAs on 2-3 subtests: Object Description (nail stimulus), Repetition, and Generative Drawing. Moreover, the mean of the $\geq 4$ group was significantly lower than the mean of at-risk participants who scored above $1 S D$ below the mean on 13 subtests: four linguistic expression subtests, three linguistic comprehension subtests, three verbal episodic memory and

Table 7. Number of participants who scored 1.5 SDs on the Arizona Battery for Communication Disorders of Dementia (ABCD) subtests as compared to healthy older adults (HOAs).

\begin{tabular}{lcc}
$\begin{array}{l}\text { Number of ABCD subtest scores } \\
\text { > 1.5 SDs below mean of HOAs }\end{array}$ & $\begin{array}{c}\text { Number of } \\
\text { participants }\end{array}$ & $\begin{array}{c}\text { Percentage of } \\
\text { participants }\end{array}$ \\
\hline 0 & 35 & 42.2 \\
1 & 18 & 21.7 \\
2 & 10 & 12.1 \\
3 & 11 & 13.3 \\
4 & 4 & 4.8 \\
5 & 3 & 3.6 \\
6 & 1 & 1.2 \\
7 & 0 & 0 \\
8 & 0 & 0 \\
9 & 1 & 1.2 \\
Total & 83 & 100.00 \\
\hline
\end{tabular}

learning subtests, both tests of visuospatial construction, and mental status.

\section{Participants Scoring Above 1 SD Below the Mean Versus Participants Scoring 1-1.5 SDs Below the Mean of $\mathrm{HOAs}$}

Noteworthy trends were observed in the data, as can be seen in Table 1. Age tended to increase as the number of below-mean performance scores increased. Moreover, a consistent gradient of lower performance scores across all subtests, except Word Learning (total recall and recognition), was apparent across the at-risk study participants. Virtually all participants performed at or near ceiling on these two measures. As the number of scores below the mean increased, mean subtest performance scores decreased (see Table 9.). Notice that, regardless of whether the study participants were low on 1, 2-3, or $\geq 4$ subtests, performance on the Repetition subtest was the subtest that was most frequently below the mean of the normative sample (see Table 8). Similarly, across all at-risk participants, performance on the same four subtests was consistently below the mean of HOAs: Repetition, Following Commands, Concept Definition, and Object Description (see Table 6). 
Table 8. Percentage of participants who scored 1.5 SDs below healthy older adults (HOAs) on each subtest and domain, by total number of scores below those of HOAs on the Arizona Battery for Communication Disorders of Dementia (ABCD) subtests.

\begin{tabular}{|c|c|c|c|c|}
\hline \multirow[b]{3}{*}{ ABCD domain and subtests } & \multicolumn{4}{|c|}{ Number of scores below $\mathrm{HOA}^{\mathrm{a}}$} \\
\hline & $\geq 1(n=48)$ & $1(n=18)$ & $2-3(n=21)$ & $\geq 4(n=9)$ \\
\hline & $\%$ & $\%$ & $\%$ & $\%$ \\
\hline \multicolumn{5}{|l|}{ Linguistic expression } \\
\hline Object Description & 25.0 & 16.7 & 23.8 & 44.4 \\
\hline Generative Naming & 6.3 & 0 & 9.5 & 11.1 \\
\hline Confrontation Naming & 8.3 & 0 & 9.5 & 22.2 \\
\hline Concept Definition & 41.7 & 11.1 & 47.6 & 88.9 \\
\hline Any subtest in domain & 62.5 & 27.8 & 76.2 & 100 \\
\hline \multicolumn{5}{|l|}{ Linguistic comprehension } \\
\hline Following Commands & 50.0 & 38.9 & 47.6 & 77.8 \\
\hline Comparative Questions & 16.7 & 5.6 & 19.1 & 33.3 \\
\hline Repetition & 41.7 & 16.7 & 52.4 & 66.7 \\
\hline Reading Comprehension: Word & 0 & 0 & 0 & 0 \\
\hline Reading Comprehension: Sentences & 16.7 & 5.6 & 14.3 & 44.4 \\
\hline Any subtest in domain & 77.1 & 66.7 & 76.2 & 100 \\
\hline \multicolumn{5}{|l|}{ Verbal episodic memory and learning } \\
\hline Story Retelling: Immediate & 10.4 & 5.6 & 9.5 & 22.2 \\
\hline Story Retelling: Delayed & 8.3 & 0 & 4.8 & 33.3 \\
\hline Word Learning: Free Recall & 4.2 & 0 & 4.8 & 11.1 \\
\hline Word Learning: Total Recall & 8.3 & 0 & 9.5 & 22.2 \\
\hline Word Learning: Recognition & 0 & 0 & 0 & 0 \\
\hline Any subtest in domain & 22.9 & 5.6 & 23.8 & 55.6 \\
\hline \multicolumn{5}{|l|}{ Visuospatial construction } \\
\hline Generative Drawing & 2.1 & 0 & 0 & 11.1 \\
\hline Figure Copying & 0 & 0 & 0 & 0 \\
\hline Any subtest in domain & 2.1 & 0 & 0 & 11.1 \\
\hline \multicolumn{5}{|l|}{ Mental status } \\
\hline Mental Status & 4.2 & 0 & 0 & 22.2 \\
\hline
\end{tabular}

\section{Discussion}

\section{Hypothesis 1: The Majority of At-Risk Participants Will Score 1 SD or More Below the Mean of HOAs on One or More Subtests}

This hypothesis was confirmed; the large majority of the at-risk individuals $(74.6 \%)$ had a performance at least $1 S D$ below the mean of HOAs on one or more ABCD subtests. Moreover, when the criterion for MCI was raised to $1.5 S D$ s below the mean of HOAs, $57.8 \%$ scored at that level on at least one ABCD subtest. Additionally, virtually a third of the sample scored 1.5 or lower on $\geq 4$ subtests. These findings underscore the importance of screening community-dwelling individuals who are able to independently carry out ADLs but are at risk for MCI by virtue of age and self-concern about cognitive change.

\section{Clinical Implications of MCI Criterion}

Clearly, the performance cutoff criterion used for diagnosing MCI has important clinical implications. If the criterion is too liberal, for example, less than $1 S D$ below typical performance of HOAs, clinicians and researchers falsely identify many people as having impairment. If the criterion is too conservative, that is, greater than $1.5 S D \mathrm{~s}$ below HOA performance, they miss identifying individuals with early impairments.

The criteria for MCI have evolved over several years (Jack et al., 2018) and continue to be debated. Whereas consensus exists that a test performance of $1 S D$ below the mean of HOAs is sufficiently improbable to raise concern, debate continues about whether there should be two or more low test scores within a cognitive domain (Jak, Bondi, et al., 2009). Several researchers report that using two scores from two tests of the same domain result in MCI diagnoses that mesh better with biomarkers for $\mathrm{AD}$ and are less likely to produce false-positive errors (Bondi \& Smith, 2014; Clark et al., 2013; Jak, Urban, et al., 2009). Similarly, other investigators argue that using a single score likely inflates MCI prevalence artificially and reduces specificity (Loewenstein et al., 2009; Trittschuh et al., 2011).

Also germane to this debate is the fact that it is not uncommon for a neurologically healthy individual to score low on one test in a battery of tests (Heaton, Miller, Taylor, \& Grant, 2004). Brooks, Iverson, Holdnack, and Feldman (2008) reported that $26 \%$ of the standardization sample of older adults for the Wechsler Memory Scale-Third Edition had one or more impaired memory scores $(\geq 1.5 S D$ s below the mean). For this reason, clinicians are encouraged to sample several cognitive domains each with more than one test to reduce false-positive errors. 
Table 9. Mean subtest scores and standard deviations of participant groups by number of scores below those of healthy older adults (HOAs) on the Arizona Battery for Communication Disorders of Dementia (ABCD) subtests.

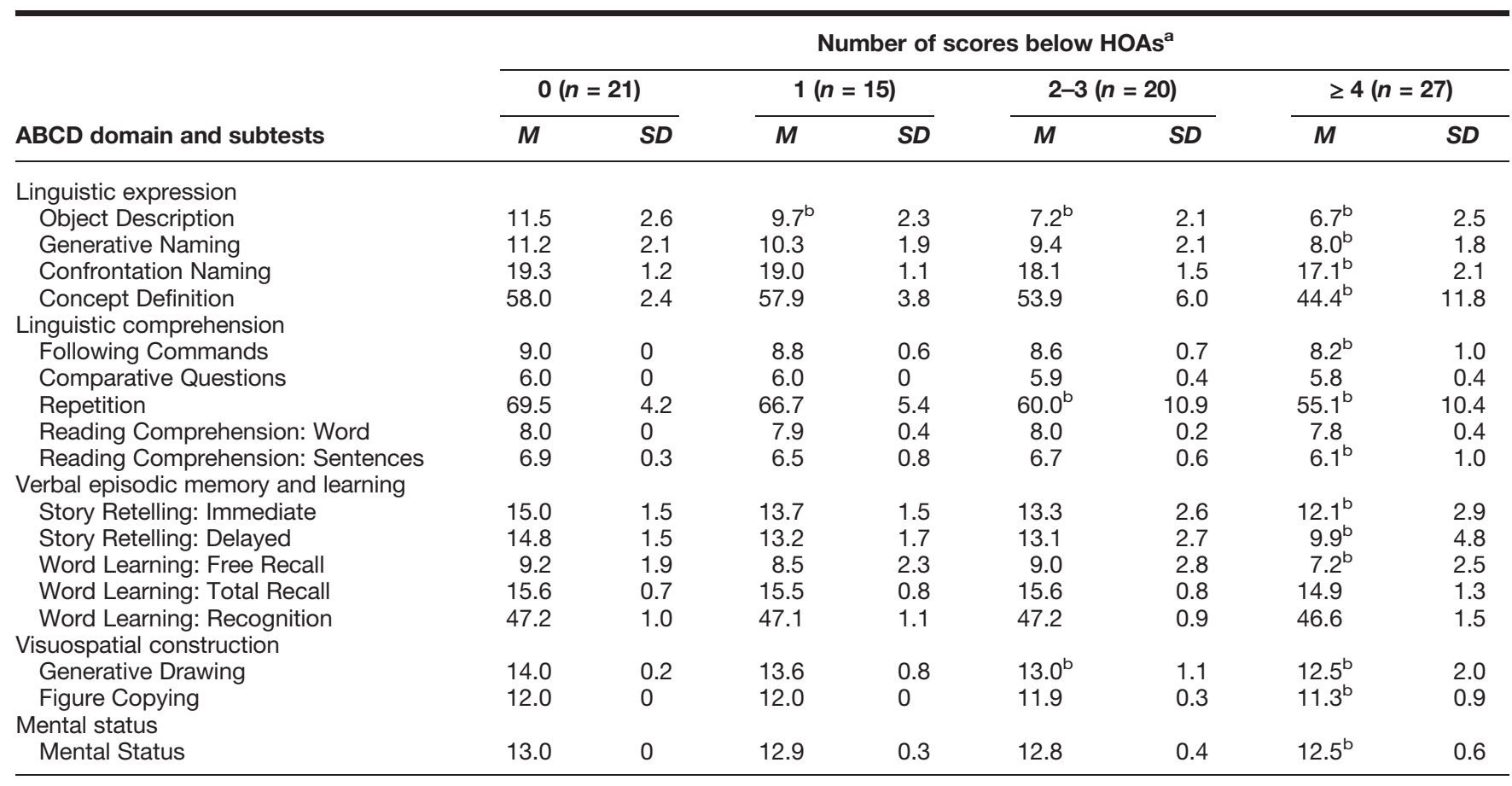

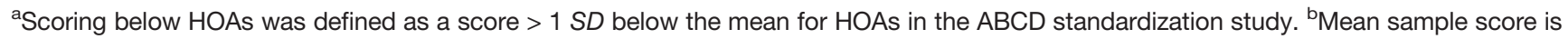
significantly lower $(p<.003)$ in the indicated group than the mean score for the group with 0 test scores below the mean of HOAs based on a one-sided $t$ test with unequal variance.

Although a single score that is $1 S D$ below the mean of HOAs satisfies the $D S M-5$ criteria for a diagnosis of MCI, it does not necessarily indicate the presence of a dementiaproducing disease. However, as the number of low test scores increases, the more concerned we are that the MCI is pathology based. Of note is the finding that having at least two scores $1 S D$ below the mean of HOAs in a cognitive domain is associated with progression to dementia (Jak et al., 2016).

Clearly, a criterion of $1.5 S D$ s below the mean gives one more confidence that an examinee is impaired, rather than a low-scoring HOA, but the issues of making a diagnosis on a single performance remain. Of the 48 participants who had one or more scores at least $1.5 S D$ s below that of HOAs, 20 participants scored at this level on three or more subtests. It is notable that participants who did perform $1.5 S D$ s below HOAs were most likely to have difficulty with linguistic expression (62.5\%) and linguistic comprehension $(77.1 \%)$ tests in contrast to memory $(22.9 \%)$ or visuospatial construction $(2.1 \%)$ tests.

Although the study participants who scored above $1 S D$ below the mean on all subtests were younger overall than those who had scores $1 S D$ or more below HOAs, they remain at risk for MCI by virtue of age and concern about cognitive status. However, it is important to note that many individuals have concern about changes in cognition that are the result of typical aging especially by middle age when episodic memory impairments, which are not disease based, are experienced (Nilsson, 2003; Tromp, Dufour, Lithfous, Pebayle, \& Després, 2015).

\section{Hypothesis 2: Language Performance Tests Will Present a Greater Challenge Than Memory, Mental Status, and Visuospatial Construction Tests}

The rationale for this hypothesis was based on reports of very early changes in language abilities, even decades before other clinical symptoms appear (Mueller et al., 2018; Ohm et al., 1995; Snowdon et al., 1996; Tsantali et al., 2013) and the fact that successful completion of language tasks requires integrity of myriad cognitive operations as well as language knowledge and processing (Dell \& O'Seaghdha, 1992; Fleming, 2014; Kirova et al., 2015; MacDonald \& Christiansen, 2002; Malek-Ahmadi et al., 2011; Martin \& Gupta, 2004; Oulhaj et al., 2009). Of the 14 ABCD subtests, the four that elicited the poorest performance were, in order, Repetition, Following Commands, Concept Definition, and Object Description. These results underscore the importance of evaluating language performance with standardized measures for which there are age-appropriate norms.

\section{Repetition Subtest}

In the Repetition subtest, examinees repeat six- and nine-syllable nonsensical phrases, for example, "quiet 
pencil jacket" and "high mountain tops chuckle sweet passion." The absence of logical meaning makes them harder to remember than logical phrases. Whereas examinees are generally successful repeating the six-syllable phrases, they typically break down when nine syllables must be recalled and repeated. Nonsensical phrases challenge the span capacity of working memory that is known to average 7 units $( \pm 2)$ of unrelated information (Miller, 1956). They also challenge linguistic expectations because they are nonsensical. Examinees must process the meaning of the words in the phrases to realize they do not make sense when so ordered, which makes the task more cognitively effortful. Because span capacity is related to cognitive aptitude (Conway, Cowan, Bunting, Therriault, \& Minkoff, 2002; Cowan et al., 2005; Cowan, Fristoe, Elliott, Brunner, $\&$ Scott Saults, 2006; Kane et al., 2004), in that cognitive manipulations are affected by the amount of information that can be held in short-term store and the rate at which it decays (Cowan, 2008), this type of test has promise as a screening measure for early detection of MCI.

Although other investigators report impairment in the ability to repeat in individuals diagnosed with MCI (Nasreddine et al., 2005; Nordlund et al., 2005), this is the first report, to our knowledge, of impairment in individuals who do not have a clinical diagnosis of MCI but are at risk by virtue of age and self-concern. Then too, the type of stimuli in the Repetition subtest differs from those used in other studies because they are semantically anomalous. In the Nasreddine et al. (2005) study, the repetition items came from the Montreal Cognitive Assessment and were two meaningful but syntactically complex sentences. In the study by Nordlund et al. (2005), the stimuli were 10 meaningful sentences of increasing length that participants were asked to repeat verbatim.

\section{Following Commands Subtest}

The second most challenging ABCD subtest for the majority of at-risk participants was Following Commands. As was the case with the Repetition subtest, the stimuli increased in difficulty from one-step commands to three-step commands. Whereas one- and two-step commands were easily executed, performance broke down when three actions had to be remembered and executed, for example, "Raise your arm, chew, then stick out your tongue." As was the case with the Repetition subtest, the three-step command likely exceeded short-term memory span capacity or decayed rapidly from short-term store, before the examinee could execute the steps of the command (Jones \& Macken, 2015).

\section{Concept Definition and Object Description Subtests}

The third and fourth most challenging tests were two language expression subtests: Concept Definition and Object Description. In Concept Definition, examinees are asked to define stimulus words. Three points can be earned on each stimulus word if at least one function and one attribute of the word are given. In Object Description, examinees are provided with a nail and instructed to describe it as completely as possible. One point is awarded for each relevant piece of information provided. Both subtests have trial items that the examiner uses to train examinees as to what constitutes a good response. Low scores on both tests indicate less idea generation than that of HOAs and support earlier findings of less idea density in written and oral narratives. This was the case with the young nuns in the study by Snowden et al. (1996) and individuals with clinically diagnosed MCI in the studies of Farias et al. (2012) and Mueller et al. (2016).

\section{Generative Naming (Verbal Fluency) Subtest}

Although we expected the Generative Naming (verbal fluency) subtest to be particularly sensitive to participants at risk of MCI, given the extensive literature reporting semantic category naming deficits in individuals with MCI (Cottingham \& Hawkins, 2010; Mirandez, Aprahamian, Talib, Forlenza, \& Radanovic, 2017), it was not among the top tasks that elicited poor performance. Nonetheless, 15 at-risk participants did perform at least $1 S D$ below HOAs on the ABCD version (modes of transportation), and 14 of these individuals scored $1 S D$ below the mean of HOAs on two or more subtests. A likely explanation for this verbal fluency task not being as challenging to the individuals who were low on less than four subtests is that it does not tax short-term memory span capacity as do the Repetition and Following Commands subtests. In short, it is cognitively less effortful. Examinees do not have to hold a series of unrelated words in consciousness in verbal fluency tasks, whereas they do in repetition tasks. Nor do they have to hold in consciousness a series of ordered commands.

\section{Episodic Memory}

Impairment in episodic memory, or "the ability to learn and retain new information," is a signature characteristic of individuals with AD and is commonly observed in individuals with MCI (Irish et al., 2011). When present in individuals with MCI, it represents a higher risk for progression to dementia (Albert et al., 2011). The ABCD subtests of Story Retelling: Immediate and Delayed and Word Learning: Free Recall are designed to assess the integrity of episodic memory. Participants $(N=27)$ whose performance was $1 S D$ below the mean of HOAs on $\geq 4$ subtests did perform statistically significantly lower, in both the immediate and delayed conditions, than at-risk participants who scored in the range of HOAs ( 0 subtests $\geq 1 S D$ ). These lower scores raised concern about possible AD pathology. Having several measures of episodic memory was valuable because we could better "stage" where individuals were on the continuum that bridges unimpaired cognition and frank dementia. We had considerably more confidence that the $\geq 4$ group were likely in the early stages of a dementing condition. 


\section{Value of Broad-Based Standardized Battery}

SLPs, psychologists, and other clinicians are increasingly evaluating at-risk individuals who do not have an established medical diagnosis of MCI. The value of using a broad-based test battery with language performance measures, as well as measures of other key cognitive abilities, as recommended by the NIA-AA MCI workgroup (Albert et al., 2011) and the American Psychiatric Association (2013), cannot be overstated. As previously noted, many etiologies are associated with MCI and can present with deficits other than memory or language impairment, for example, visual spatial impairment (Cloutier, Chertkow, Kergoat, Gauthier, \& Belleville, 2015; Fujimori et al., 1998; Possin, 2010).

As the term "mild cognitive impairment" implies, performance decrements are typically small and can be overlooked unless a broad-based battery is administered. When performance decrements are present on several measures and in more than one cognitive domain, clinicians can have more confidence in a diagnosis of MCI. However, without normative comparison data, identification of an atypical performance is problematic. An assessment battery that focuses on language comprehension and production, as well as memory and visuospatial construction abilities, for which comparison data from HOAs and individuals with probable mild symptomatic $\mathrm{AD}$ are available, gave us a more complete picture of the strengths and weaknesses of the at-risk participants in this study (Gomar et al., 2011; Jak et al., 2016).

The challenge of detecting MCI lies in identifying tests sensitive to the earliest clinical symptoms without overidentifying changes associated with healthy aging (Chapman et al., 2002). As previously noted, the ABCD was not designed to quantify knowledge or stage the level of cognitive ability like test batteries for staging intelligence. By design, ABCD test stimuli are concepts HOAs typically know and cognitive manipulations HOAs can typically do. For this reason, a performance that is at least $1 S D$ below those of HOAs, on even a single test, is a red flag for concern.

The ABCD has been used for more than 20 years primarily by SLPs and researchers for characterizing individuals with a diagnosis of dementia. This is the first report of its use with individuals at risk for MCI who have never been evaluated for cognitive impairment. In the ABCD standardization study, individuals with dementia were physician verified, community dwelling, and without hearing loss, visual problems, or depression that can confound performance. The health, vision, and hearing of the HOA control subjects were also screened, and all were in good health, literate, and able to hear and see and had no history of neurologic or psychiatric problems including depression.

Results of this study indicate that the ABCD differentiates HOAs from individuals with subtle problems whose overall performance does not meet the diagnostic criteria for dementia. Moreover, the language performance subtests of the $\mathrm{ABCD}$ were those most challenging to this group of at-risk individuals, most of whom did not exhibit verbal episodic memory impairment or changes in mental status. Then too, and importantly, 21 at-risk participants performed within the range of HOAs on all $\mathrm{ABCD}$ subtests.

\section{Language Knowledge Deficit or Language Performance Deficit}

A question we considered was how best to characterize the performance of individuals who performed below the norms of HOAs on the tests of linguistic comprehension and expression. Is poor performance best characterized as a language deficit (loss of knowledge) or a language performance deficit (cognitive-linguistic processing impairment)? Linguistic communication is cognition in action, and language production and comprehension are supported by myriad cognitive functions (Brandt, Kidd, Lieven, \& Tomasello, 2009; Kirova et al., 2015; Saunders \& Summers, 2010; Storandt, 2008; Storandt, Grant, Miller, \& Morris, 2006; Taler \& Phillips, 2008; Twamley, Legendre Ropacki, \& Bondi, 2006; Visser et al., 2008). For example, the simple task of naming a common object requires attention, perception, recognition, working memory, association, lexical retrieval, and word production. Thus, it is unsurprising that a strong correlation exists between scores on language tests and scores on tests of the cognitive functions needed to complete them (Cottingham \& Hawkins, 2010; MacDonald, 2016).

Deficits in one or more of these cognitive skills, which support communicative function, appear to be the explanation for the key findings of early language impairment in individuals with MCI, namely, deficits in discourse production and comprehension and generative and confrontation naming. Researchers recognize that verbal memory is linked to language, and a deficit in verbal recall can be observed in language performance tasks (Allen, Hitch, \& Baddeley, 2018; Cowan, 2008; Jefferies, Frankish, \& Lambon-Ralph, 2006; MacDonald, 2016). For impairment in object description, slowness in thinking and difficulty with lexical retrieval are more plausible explanations for naming fewer descriptors than actual loss of knowledge. Similarly, confrontation naming impairment can be caused by lexical access impairment rather than loss of knowledge of the name of the stimulus item, especially in individuals who are not demented. Less idea density in the written narratives of the Catholic nuns, who later developed dementia (Snowdon et al., 1996), does not imply loss of language knowledge when they were in their 20s but rather less ability to recall life experiences and generate ideas. Similarly, less grammatical complexity does not necessarily imply lack of grammatical knowledge but less skill in characterizing ideas.

Thus, the performance of individuals with MCI on various language tests may be better characterized by the term "language performance deficits" that connotes impairment in cognitive skills rather than loss of language knowledge. Use of the term "language deficit" to characterize impairment can be misleading because it implies loss of linguistic knowledge when, in fact, the cause may 
be impairment in a cognitive process such as lexical retrieval. However, regardless of whether the term "language deficit" or "language performance deficit" is used, what is clear from the results of this study is that cognitivelinguistic tasks, graduated in difficulty, such as repetition of nonmeaningful phrases, multistep verbal commands, and concept definition hold significant promise for early clinical identification of individuals with MCI.

\section{Suggested Guidelines}

Findings from this study suggest guidelines that can facilitate identification and management of individuals with MCI. First, in regard to test selection, study results support the use of a standardized comprehensive neuropsychological test battery that includes language performance measures. Second, study results support the use of tests for which there are performance data for healthy peers and individuals who meet the diagnostic criteria for mild Alzheimer's dementia. Third, they support the inclusion of tests that have a gradient of difficulty that enables clinicians to detect subtle impairments. Fourth, they reveal that most individuals who score below HOAs on one measure also score below HOAs on other measures, thereby substantiating the value of using several measures.

Regarding test performance interpretation, clinicians should consider (a) the degree of deviance of an individual's test performance from the mean of healthy peers with similar education, (b) the number of low test scores in a cognitive domain, (c) the number of cognitive domains affected, (d) the type of cognitive domain(s) affected, and (e) the ability of the individual to perform instrumental ADLs (IADLs). Whereas a single score that is $1 S D$ below the mean of HOAs (that is not in the domain of episodic memory) is not uncommon in a neurologically healthy person who can perform IADLs, two low scores are uncommon. Further, it is also uncommon for an HOA to have low scores in more than one cognitive domain. For those individuals, with one or more low scores, we recommend that they be carefully questioned about their ability to perform IADLs. If the individual reports difficulty, that is additional evidence for pathology.

The type of deficit and domain affected can give clinicians insight as to possible pathology. For example, a deficit in delayed recall is a red flag for possible AD; a deficit in visual spatial function is a red flag for possible Lewy body disease; and a deficit in language, in the absence of stroke, is a red flag for primary progressive aphasia.

When advising examinees who have a single low (nonepisodic memory) test score, we explain that a single low score is not uncommon in cognitively healthy elderly people. Nonetheless, we recommend a medical examination and retesting in a year or sooner if the individual senses decline. For those with more than one low score, the value of a medical examination is emphasized and retesting in 6 months is strongly recommended.

Regardless of performance, however, we recommend that clinicians educate clients who have concern about their cognitive function, of the benefit of cognitive stimulation, namely, the strengthening of cognitive reserve. Then too, we recommend lifestyle choices that support brain health such as regular exercise, sufficient sleep, and a diet high in antioxidants and low in sugar. Finally, individuals with concern about their cognitive function should be informed that physicians can do biomarker testing because research has shown that individuals who express concern regarding change in memory or language are at an increased risk of developing cognitive impairment (Perrotin et al., 2017; Snitz et al., 2018; Tripodis et al., 2017).

As is often the case, the results of this study would be more meaningful were the sample size larger. However, the most significant limitation of the study was not having the luxury of longitudinal follow-up. Such a study would be valuable in helping clinicians understand the significance of a single low score versus two or more low scores, especially when they use a liberal criterion for impairment. Further, it would provide information about rate of change in various cognitive functions. Then too, little is known about the length of the MCI stage when the pathology is AD. Longitudinal data could provide this needed information.

Another study limitation was the absence of biomarker data for study participants that would increase confidence in the interpretation of test performance patterns. However, clinicians will find themselves faced with clients who are concerned about MCI because of their age or a sense that their cognitive function has changed for whom there are no biomarker data available. We hope that the data from this study of similar at-risk individuals will help clinicians conduct a valid assessment.

\section{Acknowledgments}

Portions of this work have been supported by internal grants through Appalachian State University and the University of Central Arkansas. The authors thank the individuals who served as participants.

\section{References}

Ahmed, S., Arnold, R., Thompson, S. A., Graham, K. S., \& Hodges, J. R. (2008). Naming of objects, faces and buildings in mild cognitive impairment. Cortex, 44(6), 746-752.

Albert, M. S., DeKosky, S. T., Dickson, D., Dubois, B., Feldman, H. H., Fox, N. C., ... Phelps, C. H. (2011). The diagnosis of mild cognitive impairment due to Alzheimer's disease: Recommendations from the National Institute on Aging-Alzheimer's Association workgroups on diagnostic guidelines for Alzheimer's disease. Alzheimer's \& Dementia, 7(3), 270-279. https://doi.org/ 10.1016/j.jalz.2011.03.008

Allen, R. J., Hitch, G. J., \& Baddeley, A. D. (2018). Exploring the sentence advantage in working memory: Insights from serial recall and recognition. Quarterly Journal of Experimental Psychology, 71, 2571-2585. https://doi.org/10.1177/1747021817746929

Alzheimer's Association. (2018). Alzheimer's disease facts and figures 2018 report. Retrieved from https://www.alz.org/facts/

Alzheimer's Disease International. (2015). World Alzheimer report 2015. Retrieved from https://www.alz.co.uk/research/world-report-2015 
American Psychiatric Association. (2013). Diagnostic and statistical manual of mental disorders (5th ed.). Arlington, VA: American Psychiatric Publishing.

Asgari, J., Kaye, H., \& Dodge, H. (2017). Predicting mild cognitive impairment from spontaneous spoken utterances. Alzheimer's \& Dementia: Translational Research \& Clinical Interventions, 3(2), 219-228.

Bayles, K. A., McCullough, K. C., \& Tomoeda, C. K. (2018). Cognitive-communication disorders of dementia. San Diego, CA: Plural.

Bayles, K. A., \& Tomoeda, C. K. (1993). Arizona Battery for Communication Disorders of Dementia. Austin, TX: Pro-Ed.

Bayles, K. A., Tomoeda, C. K., \& Trosset, M. W. (1992). Relation of linguistic communication abilities of Alzheimer's patients to stage of disease. Brain and Language, 42, 454- 472.

Bayles, K. A., Tomoeda, C. K., \& Trosset, M. W. (1993). Alzheimer's disease: Effects on language. Developmental Neuropsychology, 9, 131-160.

Bayles, K. A., Tomoeda, C. K., Wood, J. A., Cruz, R. F., \& Mcgeagh, A. (1996). Comparison of the sensitivity of the ABCD and other measures to Alzheimer's dementia. Journal of Medical Speech-Language Pathology, 4, 183-194.

Bayles, K. A., Trosset, M. W., Tomoeda, C. K., Montgomery, E. B., Jr., \& Wilson, J. (1993). Generative naming in Parkinson disease patients. Journal of Clinical and Experimental Neuropsychology, 15(4), 547-562. https://doi.org/10.1080/01688639308402578

Bertola, L., Cunha Lima, M. L., Romano-Silva, M. A., de Moraes, E. N., Diniz, B. S., \& Malloy-Diniz, L. F. (2014). Impaired generation of new subcategories and switching in a semantic verbal fluency test in older adults with mild cognitive impairment. Frontiers in Aging Neuroscience, 6, 141. https://doi.org/ 10.3389/fnagi.2014.00141

Bondi, M. W., \& Smith, G. E. (2014). Mild cognitive impairment: A concept and diagnostic entity in need of input from neuropsychology. Journal of the International Neuropsychological Society, 20(2), 129-134. https://doi.org/10.1017/S1355617714000010

Brandt, S., Kidd, E., Lieven, E., \& Tomasello, M. (2009). The discourse bases of relativization: An investigation of young German and English-speaking children's comprehension of relative clauses. Cognitive Linguistics, 20(3), 539-570.

Brooks, B. L., Iverson, G. L., Holdnack, J. A., \& Feldman, H. H. (2008). Potential for misclassification of mild cognitive impairment: A study of memory scores on the Wechsler Memory Scale-III in healthy older adults. Journal of the International Neuropsychological Society, 14(3), 463-478. https://doi.org/ 10.1017/S1355617708080521

Bruscoli, M., \& Lovestone, S. (2004). Is MCI really just early dementia? A systematic review of conversion studies. International Psychogeriatric Association, 16(2), 129-140.

Cardoso, S., Silva, D., Maroco, J., de Mendonça, A., \& Guerreiro, M. (2014). Non-literal language deficits in mild cognitive impairment. Psychogeriatrics, 14(4), 222-228. https://doi.org/10.1111/ psyg. 12101

Chapman, S. B., Zientz, J., Weiner, M., Rosenberg, R., Frawley, W., \& Burns, M. H. (2002). Discourse changes in early Alzheimer disease, mild cognitive impairment, and normal aging. Alzheimer Disease and Associated Disorders, 16(3), 177-186.

Chen, W., \& Wang, H. (2013). Mild cognitive impairment: A concept useful for early detection and intervention of dementia. Shanghai Archives of Psychiatry, 25(2), 119-120.

Choi, H., Kim, J. H., Lee, C. M., \& Kim, J. I. (2013). Features of semantic language impairment in patients with amnestic mild cognitive impairment. Dementia and Neurocognitive Disorders, 12(2), 33-40. https://doi.org/10.12779/dnd.2013.12.2.33
Chong, M. S., \& Sahadevan, S. (2005). Preclinical Alzheimer's disease: Diagnosis and prediction of progression. The Lancet. Neurology, 4(9), 576-579.

Clark, L. R., Delano-Wood, L., Libon, D. J., McDonald, C. R., Nation, D. A., Bangen, K. J., ... Bondi, M. W. (2013). Are empirically-derived subtypes of mild cognitive impairment consistent with conventional subtypes. Journal of the International Neuropsychological Society, 19(6), 635-645. https://doi.org/ $10.1017 / \mathrm{S} 1355617713000313$

Cloutier, S., Chertkow, H., Kergoat, M. J., Gauthier, S., \& Belleville, S. (2015). Patterns of cognitive decline prior to dementia in persons with mild cognitive impairment. Journal of Alzheimer's Disease, 47(4), 901-913. https://doi.org/10.3233/ JAD-142910

Conway, A. R. A., Cowan, N., Bunting, M. F., Therriault, D. J., \& Minkoff, S. R. B. (2002). A latent variable analysis of working memory capacity, short-term memory capacity, processing speech, and general fluid intelligence. Intelligence, 30(2), 163-183.

Costa, A., Monaco, M., Zabberoni, S., Peppe, A., Perri, R., Fadda, L., ... Carlesimo, G. A. (2014). Free and cued recall memory in Parkinson's disease associated with amnestic mild cognitive impairment. PLoS One, 9(1), e86233. https://doi.org/10.1371/ journal.pone.0086233

Cottingham, M. E., \& Hawkins, K. A. (2010). Verbal fluency deficits co-occur with memory deficits in geriatric patients at risk for dementia: Implications for the concept of mild cognitive impairment. Behavioural Neurology, 22(3-4), 73-79.

Cowan, N. (2008). What are the differences between long-term, short-term, and working memory. Progress in Brain Research, 169, 323-338. https://doi.org/10.1016/S0079-6123(07)00020-9

Cowan, N., Elliott, E. M., Scott Saults, J., Morey, C. C., Mattox, S., Hismjatullina, A., \& Conway, A. R. (2005). On the capacity of attention: Its estimation and its role in working memory and cognitive aptitudes. Cognitive Psychology, 51(1), 42-100. https:// doi.org/10.1016/j.cogpsych.2004.12.001

Cowan, N., Fristoe, N. M., Elliott, E. M., Brunner, R. P., \& Scott Saults, J. (2006). Scope of attention, control of attention, and intelligence in children and adults. Memory \& Cognition, 34(8), 1754-1768.

Dell, G. S., \& O, Seaghdha, P. G. (1992). Stages of lexical access in language production. Cognition, 42(1-3), 287-314.

Demetriou, E., \& Holtzer, R. (2017). Mild cognitive impairments moderate the effect of time on verbal fluency performance. Journal of the International Neuropsychological Society, 23, 44-55.

Díaz-Mardomingo, M. D. C., García-Herranz, S., Rodríguez-Fernández, R., Venero, C., \& Peraita, H. (2017). Problems in classifying mild cognitive impairment (MCI): One or multiple syndromes. Brain Sciences, 7(9), E111.

Dubois, B., Hampel, H., Feldman, H. H., Scheltens, P., Aisen, P., Andrieu, S., ... Proceedings of the Meeting of the International Working Group (IWG) and the American Alzheimer's Association on "The preclinical state of AD." (2016). Preclinical Alzheimer's disease: Definition, natural history, and diagnostic criteria. Alzheimer's \& Dementia, 12(3), 292-323. https://doi.org/10.1016/ j.jalz.2016.02.002

Dunn, O. J. (1961). Multiple comparisons among means. Journal of the American Statistical Association, 56(293), 52-64.

Dwolatzky, T., Whitehead, V., Doniger, G. M., Simon, E. S., Schweiger, A., Jaffe, D., \& Chertkow, H. (2003). Validity of a novel computerized cognitive battery for mild cognitive impairment. BMC Geriatrics, 3, 4. https://doi.org/10.1186/1471-2318-3-4

Farias, S. T., Chand, V., Bonnici, L., Baynes, K., Harvey, D., Mungas, D., ... Reed, B. (2012). Idea density measured in late 
life predicts subsequent cognitive trajectories: Implications for the measurement of cognitive reserve. Journals of Gerontology: Series B: Psychological Sciences and Social Sciences, 67(6), 677-686. https://doi.org/10.1093/geronb/gbr162

Fleming, V. B. (2014). Early detection of cognitive-linguistic change associated with mild cognitive impairment. Communication Disorders Quarterly, 35(3), 146-157.

Folstein, M. F., Folstein, S. E., \& McHugh, P. R. (1975). "Minimental state": A practical method for grading the cognitive state of patients for the clinician. Journal of Psychiatric Research, 12(3), 189-198.

Fujimori, M., Imamura, T., Yamashita, H., Hirono, N., Ikejiri, Y., Shimomura, T., \& Mori, E. (1998). Age at onset and visuocognitive disturbances in Alzheimer disease. Alzheimer Disease and Associated Disorders, 12(3), 163-166.

Gomar, J. J., Bobes-Bascaran, M. T., Conejero-Goldberg, C., Davies, P., Goldberg, T. E., \& Alzheimer's Disease Neuroimaging Initiative. (2011). Utility of combinations of biomarkers, cognitive markers, and risk factors to predict conversion from mild cognitive impairment to Alzheimer disease in patients in the Alzheimer's disease neuroimaging initiative. Archives of General Psychiatry, 68(9), 961-969. https://doi.org/10.1001/ archgenpsychiatry.2011.96

Gorelick, P. B., Furie, K. L., Iadecola, C., Smith, E. E., Waddy, S. P., Lloyd-Jones, D. M., ... Zerna, C. (2017). Defining optimal brain health in adults: A presidential advisory from the American Heart Association/American Stroke Association. Stroke, 48(10), 284-303. https://doi.org/10.1161/STR.0000000000000148

Grundman, M., Petersen, R. C., Ferris, S. H., Thomas, R. G., Aisen, P. S., Bennett, D. A., ... Thal, L. J. (2004). Mild cognitive impairment can be distinguished from Alzheimer disease and normal aging for clinical trials. Archives of Neurology, 61(1), 59-66. https://doi.org/10.1001/archneur.61.1.59

Hachinski, V. C., Iliff, L. D., Zilhka, E., Du Boulay, G. H., McAllister, V. L., Marshall, J., ... Symon, L. (1975). Cerebral blood flow in dementia. Archives of Neurology, 32, 632-637.

Hane, F. T., Robinson, M., Lee, B. Y., Bai, O., Leonenko, Z., \& Albert, M. S. (2017). Recent progress in Alzheimer's disease research, Part 3: Diagnosis and treatment. Journal of Alzheimer's Disease, 57(3), 645-665.

Hart, R. P., Kwentus, J. A., Wade, J. B., \& Taylor, J. R. (1988). Modified Wisconsin Sorting Test in elderly normal, depressed and demented patients. Clinical Neuropsychologist, 2(1), 49-56. https://doi.org/10.1080/13854048808520085

Heaton, R. K., Miller, S. W., Taylor, M. J., \& Grant, I. (2004). Revised comprehensive norms for an expanded Halstead-Reitan battery: Demographically adjusted neuropsychological norms for African American and Caucasian adults. Lutz, FL: Psychological Assessment Resources.

Irish, M., Hornberger, M., Lah, S., Miller, L., Pengas, G., Nestor, P. J., ... Piguet, O. (2011). Profiles of recent autobiographical memory retrieval in semantic dementia, behavioural-variant frontotemporal dementia, and Alzheimer's disease. Neuropsychologia, 49(9), 2694-2702.

Jack, C. R., Jr., Bennett, D. A., Blennow, K., Carrillo, M. C., Dunn, B., Haeberlein, S. B., ... Sperling, R. (2018). NIA-AA Research Framework: Toward a biological definition of Alzheimer's disease. Alzheimer's \& Dementia, 14(4), 535-562. https://doi.org/ 10.1016/j.jalz.2018.02.018

Jack, C. R., Jr., Lowe, V. J., Senjem, M. L., Weigand, S. D., Kemp, B. J., Shiung, M. M., ... Petersen, R. C. (2008). ${ }^{11} \mathrm{C}$ $\mathrm{PiB}$ and structural MRI provide complementary information in imaging of $\mathrm{AD}$ and amnestic mild cognitive impairment. Brain, 131(3), 665-680. https://doi.org/10.1093/brain/awm336
Jak, A. J., Bondi, M. W., Delano-Wood, L., Wierenga, C., Corey-Bloom, J., Salmon, D. P., \& Delis, D. C. (2009). Quantification of five neuropsychological approaches to defining mild cognitive impairment. The American Journal of Geriatric Psychiatry, 17(5), 368-375. https://doi.org/10.1097/ JGP.0b013e31819431d5

Jak, A. J., Preis, S. R., Beiser, A. S., Seshadri, S., Wolf, P. A., Bondi, M. W., \& Au, R. (2016). Neuropsychological criteria for mild cognitive impairment and dementia risk in the Framingham Heart Study. Journal of the International Neuropsychological Society, 22(9), 937-943. https://doi.org/10.1017/S1355617716000199

Jak, A. J., Urban, S., Mccauley, A., Bangen, K. J., Delano-Wood, L., Corey-Bloom, J., \& Bondi, M. W. (2009). Profile of hippocampal volumes and stroke risk varies by neuropsychological definition of mild cognitive impairment. Journal of the International Neuropsychological Society, 15(6), 890-897. https://doi.org/10.1017/ S1355617709090638

Jefferies, E., Frankish, C. R., \& Lambon-Ralph, M. A. (2006). Lexical and semantic binding in verbal short-term memory. Journal of Memory and Language, 54, 81-98. https://doi.org/ 10.1016/j.jml.2005.08.001

Johnson, S. C., Koscik, R. L., Jonaitis, E. M., Clark, L. R., Mueller, K. D., Berman, S. E., ... Sager, M. A. (2017). The Wisconsin registry for Alzheimer's prevention: A review of findings and current directions. Alzheimer's \& Dementia: Diagnosis, Assessment \& Disease Monitoring, 10, 130-142. https://doi.org/ 10.1016/j.dadm.2017.11.007

Jones, G., \& Macken, B. (2015). Questioning short-term memory and its measurement: Why digit span measures long-term associative learning. Cognition, 144, 1-13. https://doi.org/10.1016/j. cognition.2015.07.009

Kane, M. J., Hambrick, D. Z., Tuholski, S. W., Wilhelm, O., Payne, T. W., \& Engle, R. W. (2004). The generality of working memory capacity: A latent-variable approach to verbal and visuospatial memory span and reasoning. Journal of Experimental Psychology: General, 133(2), 189-217. https://doi. org/10.1037/0096-3445.133.2.189

Keyimu, K., Zhou, X.-H., Miao, H.-J., \& Zou, T. (2015). Mild cognitive impairment risk factor survey of the Xinjiang Uyghur and Han elderly. International Journal of Clinical and Experimental Medicine, 8(8), 13891-13900.

Kim, J. K., Sung, J. E., \& Jeong, J. H. (2012). Effects of syntactic complexity on sentence comprehension in persons with mild cognitive impairment and dementia of Alzheimer's type. Communication Sciences \& Disorders, 17, 338-355.

Kirova, A.-M., Bays, R. B., \& Lagalwar, S. (2015). Working memory and executive function decline across normal aging, mild cognitive impairment, and Alzheimer's disease. BioMed Research International, 2015, 748212. https://doi.org/10.1155/ 2015/748212

Livingston, G., Sommerlad, A., Orgeta, V., Costafreda, S. G., Huntley, J., Ames, D., Ballard, C., ... Mukadam, N. (2017). Dementia prevention, intervention and care. Lancet, 390(10113), 2673-2734. https://doi.org/10.1016/S0140-6736(17)31363-6

Loewenstein, D. A., Acevedo, A., Small, B. J., Agron, J., Crocco, E., \& Duara, R. (2009). Stability of different subtypes of mild cognitive impairment among the elderly over a 2- to 3-year follow-up period. Dementia and Geriatric Cognitive Disorders, 27(5), 418-423. Retrieved from https://login.proxy006.nclive. org/login?url=https://search.proquest.com/docview/232508580? accountid $=8337$

Loftus, A. M. (2017). Risk factors for mild cognitive impairment (MCI). Brain Sciences, 7(9), 117. https://doi.org/10.3390/ brainsci7090117 
MacDonald, M. C. (2016). Speak, act, remember: The languageproduction basis of serial order and maintenance in verbal memory. Current Directions in Psychological Science, 25(1), 47-53. https://doi.org/10.1177/0963721415620776

MacDonald, M. C., \& Christiansen, M. H. (2002). Reassessing working memory: Comment on Just and Carpenter (1992) and Waters and Caplan (1996). Psychological Review, 109(1), 35-54. https://doi.org/10.1037/0033-295X.109.1.35

Malek-Ahmadi, M., Raj, A., \& Small, B. J. (2011). Semantic clustering as a neuropsychological predictor for amnestic-MCI. Neuropsychology, Development, and Cognition. Section B, Aging, Neuropsychology and Cognition, 18(3), 280-292.

Martin, N., \& Gupta, P. (2004). Exploring the relationship between word processing and verbal short-term memory: Evidence from associations and dissociations. Cognitive Neuropsychology, 21(2), 213-228. https://doi.org/10.1080/02643290342000447

Miller, G. A. (1956). The magical number seven plus or minus two: Some limits on our capacity for processing information. Psychological Review, 63(2), 81-97.

Mirandez, R. M., Aprahamian, I., Talib, L. L., Forlenza, O. V., \& Radanovic, M. (2017). Multiple category verbal fluency in mild cognitive impairment and correlation with CSF biomarkers for Alzheimer's disease. International Psychogeriatrics, 29(6), 949-958.

Mueller, K. D., Koscik, R. L., Hermann, B. P., Johnson, S. C., \& Turkstra, L. S. (2018). Declines in connected language are associated with very early mild cognitive impairment: Results from the Wisconsin registry for Alzheimer's prevention. Frontiers in Aging Neuroscience, 9, 437. https://doi.org/10.3389/ fnagi.2017.00437

Mueller, K. D., Koscik, R. L., LaRue, A., Clark, L. R., Hermann, B., Johnson, S. C., \& Sager, M. A. (2015). Verbal fluency and early memory decline: Results from the Wisconsin registry for Alzheimer's prevention. Archives of Clinical Neuropsychology, 30, 448-457.

Mueller, K. D., Koscik, R. L., Turkstra, L. S., Riedeman, S. K., LaRue, A., Clark, L. R., ... Johnson, S. C. (2016). Connected language in late middle-aged adults at risk for Alzheimer's disease. Journal of Alzheimer's Disorders, 54(4), 1539-1550.

Nasreddine, Z. S., Phillips, N. A., Bédirian, V., Charbonneau, S., Whitehead, V., Collin, I., ... Chertkow, H. (2005). The Montreal Cognitive Assessment, MoCA: A brief screening tool for mild cognitive impairment. Journal of the American Geriatrics Society, 53(4), 695-699.

Ngandu, T., Lehtisalo, J., Solomon, A., Levälahti, E., Ahtiluoto, S., Antikainen, R., ... Kivipelto, M. (2015). A 2 year multidomain intervention of diet, exercise, cognitive training, and vascular risk monitoring versus control to prevent cognitive decline in at-risk elderly people (FINGER): A randomised controlled trial. Lancet, 385(9984), 2255-2263. https://doi.org/10.1016/ S0140-6736(15)60461-5

Nilsson, L. G. (2003). Memory function in normal aging. Acta Neurologica Scandinavica. Supplementum, 179, 7-13.

Nordlund, A., Rolstad, S., Hellström, P., Sjögren, M., Hansen, S., \& Wallin, A. (2005). The Goteborg MCI study: Mild cognitive impairment is a heterogeneous condition. Journal of Neurology, Neurosurgery, \& Psychiatry, 76(11), 1485-1490.

Nutter-Upham, K. E., Saykin, A. J., Rabin, L. A., Roth, R. M., Wishart, H. A., Pare, N., \& Flashman, L. A. (2008). Verbal fluency performance in amnestic MCI and older adults with cognitive complaints. Archives of Clinical Neuropsychology, 23(3), 229-241. https://doi.org/10.1016/j.acn.2008.01.005

Nyberg, L., \& Bäckman, L. (2011). Memory changes and the aging brain: A multimodal imaging approach. In K. W. Schaie \&
S. L. Willis (Eds.), Handbook of the psychology of aging (pp. 121-131). San Diego, CA: Elsevier Press.

Ohm, T. G., Müller, H., Braak, H., \& Bohl, J. (1995). Closemeshed prevalence rates of different stages as a tool to uncover the rate of Alzheimer's disease-related neurofibrillary changes. Neuroscience, 64(1), 209-217.

Oulhaj, A., Wilcock, G. K., Smith, A. D., \& de Jager, C. A. (2009). Predicting the time of conversion to MCI in the elderly: Role of verbal expression and learning. Neurology, 73(18), 1436-1442.

Payne, B. R., \& Stine-Morrow, E. A. L. (2016). Risk for mild cognitive impairment is associated with semantic integration deficits in sentence processing and memory. Journals of Gerontology: Series B: Psychological Sciences and Social Sciences, 71(2), 243-253. https://doi.org/10.1093/geronb/gbu103

Perrotin, A., La Joie, R., de La Sayette, V., Barré, L., Mézenge, F., Mutlu, J., ... Chételat, G. (2017). Subjective cognitive decline in cognitively normal elders from the community or from a memory clinic: Differential affective and imaging correlates. Alzheimer's \& Dementia, 13(5), 550-560. https://doi.org/ 10.1016/j.jalz.2016.08.011

Peters, R. (2006). Ageing and the brain. Postgraduate Medical Journal, 82(964), 84-88. https://doi.org/10.1136/pgmj.2005. 036665

Petersen, R. C. (2004). Mild cognitive impairment as a diagnostic entity. Journal of Internal Medicine, 256, 183-194. https://doi. org/10.1111/j.1365-2796.2004.01388.x

Petersen, R. C., Caracciolo, B., Brayne, C., Gauthier, S., Jelic, V., \& Fratiglioni, L. (2014). Mild cognitive impairment: A concept in evolution. Journal of Internal Medicine, 275(3), 214-228. https://doi.org/10.1111/joim.12190

Petersen, R. C., \& Negash, S. (2008). Mild cognitive impairment: An overview. CNS Spectrums, 13, 45-53. https://doi.org/10.1017/ S1092852900016151

Petersen, R. C., Smith, G. E., Waring, S. C., Ivnik, R. J., Tangalos, E. G., \& Kokmen, E. (1999). Mild cognitive impairment: Clinical characterization and outcome. Archives of Neurology, 56(3), 303-308. https://doi.org/10.1001/archneur.56.3.303

Possin, K. L. (2010). Visual spatial cognition in neurodegenerative disease. Neurocase, 16(6), 466-487. https://doi.org/10.1080/ 13554791003730600

Reisberg, B., Ferris, S. H., de Leon, M. J., \& Crook, T. (1982). The Global Deterioration Scale for assessment of primary degenerative dementia. American Journal of Psychiatry, 139(9), 1136-1139. https://doi.org/10.1176/ajp.139.9.1136

Reisberg, B., Ferris, S. H., de Leon, M. J., \& Crook, T. (1998). The global deterioration scale (GDS): An instrument for the assessment of primary degenerative dementia. American Journal of Psychiatry, 139, 1136-1139.

Riley, K. P., Snowdon, D. A., Desrosiers, M. F., \& Markesbery, W. R. (2005). Early life linguistic ability, late life cognitive function, and neuropathology: Findings from the Nun Study. Neurobiology of Aging, 26(3), 341-347.

Roth, M., Huppert, F. A., Tym, E., \& Mountjoy, C. Q. (1988). CAMDEX: The Cambridge Examination for Mental Disorders of the Elderly. Cambridge, United Kingdom: Cambridge University Press.

Sachdev, P. S., Blacker, D., Blazer, D. G., Ganguli, M., Jeste, D. V., Paulsen, J. S., \& Petersen, R. C. (2014). Classifying neurocognitive disorders: The DSM-5 approach. Nature Reviews. Neurology, 10, 634-642.

Saunders, N. L., \& Summers, M. J. (2010). Attention and working memory deficits in mild cognitive impairment. Journal of Clinical and Experimental Neuropsychology, 32(4), 350-357. 
Savica, R., Rocca, W. A., \& Ahlskog, J. E. (2010). When does Parkinson disease start? Archives of Neurology, 67(7), 798-801. https://doi.org/10.1001/archneurol.2010.135

Smolik, F., Stepankova, H., Vyhnálek, M., Nikolai, T., Horáková, K., \& Matejka, Š. (2016). Propositional density in spoken and written language of Czech-speaking patients with mild cognitive impairment. Journal of Speech, Language, and Hearing Research, 59(6), 1461-1470. https://doi.org/10.1044/2016_JSLHR-L-15-0301

Snitz, B. E., Wang, T., Cloonan, Y. K., Jacobsen, E., Chang, C. H., Hughes, T. F., .. . Ganguli, M. (2018). Risk of progression from subjective cognitive decline to mild cognitive impairment: The role of study setting. Alzheimer's Dementia, 14(6), 734-742. https://doi.org/10.1016/j.jalz.2017.12.003

Snowdon, D. A., Kemper, S. J., Mortimer, J. A., Greiner, L. H., Wekstein, D. R., \& Markesbery, W. R. (1996). Linguistic ability in early life and cognitive function and Alzheimer's disease in late life: Findings from the Nun Study. JAMA, 275(7), 528-532.

Sperling, R. A., Aisen, P. S., Beckett, L. A., Bennett, D. A., Craft, S., Fagan, A. M., ... Phelps, C. H. (2011). Toward defining the preclinical stages of Alzheimer's disease: Recommendations from the National Institute on Aging-Alzheimer's Association workgroups on diagnostic guidelines for Alzheimer's disease. Alzheimer's \& Dementia, 7(3), 280-292.

Sperling, R. A., Karlawish, J., \& Johnson, K. A. (2013). Preclinical Alzheimer disease-The challenges ahead. Nature Reviews. Neurology, 9(1), 54-58. https://doi.org/10.1038/nrneurol.2012.241

Storandt, M. (2008). Cognitive deficits in the early stages of Alzheimer's disease. Current Directions in Psychological Science, 17(3), 198-202.

Storandt, M., Grant, E. A., Miller, J. P., \& Morris, J. C. (2006). Longitudinal course and neuropathologic outcomes in original vs revised MCI and in pre-MCI. Neurology, 67(3), 467-473.

Taler, V., \& Phillips, N. A. (2008). Language performance in Alzheimer's disease and mild cognitive impairment: A comparative review. Journal of Clinical and Experimental Neuropsychology, 30(5), 501-556.

Tomoeda, C. K., \& Bayles, K. A. (1993). Longitudinal effects of Alzheimer's disease on discourse production. Alzheimer Disease and Associated Disorders, 7(4), 223-236.

Tomoeda, C. K., Bayles, K. A., Trosset, M. W., Azuma, T., \& McGeagh, A. (1996). Cross-sectional analysis of Alzheimer disease effects on oral discourse in a picture description task. Alzheimer Disease and Associated Disorders, 10(4), 204-215.
Tripodis, Y., Coleman, B., Martin, B. M., Chaisson, C. E., Steinberg, E., Kowall, N. W., ... Stern, R. A. (2017). Significant subjective memory and language complaints predict conversion to MCI and Alzheimer's disease dementia. Alzheimer's \& Dementia, 13(7), 743.

Trittschuh, E. H., Crane, P. K., Larson, E. B., Cholerton, B., McCormick, W. C., McCurry, S. M., ... Craft, S. (2011). Effects of varying diagnostic criteria on prevalence of mild cognitive impairment in a community based sample. Journal of Alzheimer's Diseases, 25(1), 163-173. https://doi.org/10.3233/ JAD-2011-101821

Tromp, D., Dufour, A., Lithfous, S., Pebayle, T., \& Després, O. (2015). Episodic memory in normal aging and Alzheimer disease: Insights from imaging and behavioral studies. Ageing Research Reviews, 24, 232-262. https://doi.org/10.1016/j.arr. 2015.08.006

Tsantali, E., Economidis, D., \& Tsolaki, M. (2013). Could language deficits really differentiate mild cognitive impairment (MCI) from mild Alzheimer's disease. Archives of Gerontology and Geriatrics, 57(3), 263-270.

Twamley, E. W., Legendre Ropacki, S. A., \& Bondi, M. W. (2006). Neuropsychological and neuroimaging changes in preclinical Alzheimer's disease. Journal of the International Neuropsychological Society, 12(5), 707-735.

Varghese, T., Sheelakumari, R., James, J. S., \& Mathuranath, P. S. (2013). A review of neuroimaging biomarkers of Alzheimer's disease. Neurology Asia, 18(3), 239-248.

Vaughan, R. M., Coen, R. F., Kenny, R., \& Lawlor, B. A. (2016). Preservation of the semantic verbal fluency advantage in a large population-based sample: Normative data from the TILDA study. Journal of the International Neuropsychological Society, 22(5), 570-576. https://doi.org/10.1017/ S1355617716000291

Visser, P. J., Verhey, F. R., Boada, M., Bullock, R., De Deyn, P. P., Frisoni, G. B., ... Winblad, B. (2008). Development of screening guidelines and clinical criteria for predementia Alzheimer's disease. The DESCRIPA study. Neuroepidemiology, 30(4), 254 265. https://doi.org/10.1159/000135644

Weakley, A., Schmitter-Edgecombe, M., \& Anderson, J. (2013). Analysis of verbal fluency ability in amnestic and non-amnestic mild cognitive impairment. Archives of Clinical Neuropsychology, 28(7), 721-731. https://doi.org/10.1093/arclin/act058

Wechsler, D. (1981). WAIS-R: Wechsler Adult Intelligence ScaleRevised. New York, NY: Psychological Corporation. 